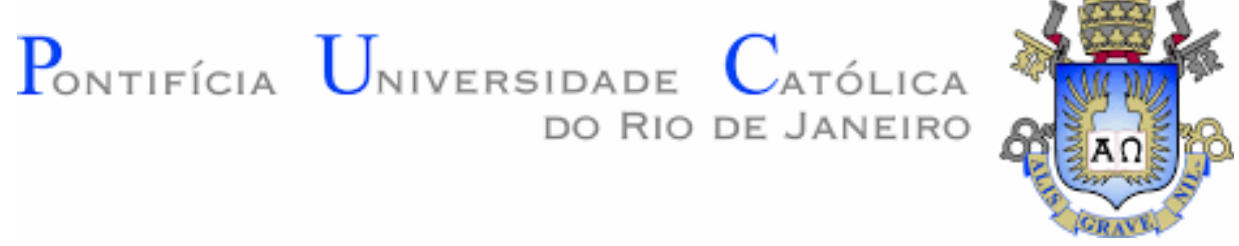

Robson Luiz Macedo

\begin{abstract}
AVALIAÇÃO DE MODELOS DE PRECIFICAÇÃO DE ATIVOS NO MERCADO ACIONÁRIO BRASILEIRO AÇÕES DO BANCO DO BRASIL S.A (BBAS3)
\end{abstract}

Dissertação de Mestrado

Dissertação apresentada ao Programa de Pós-graduação em Administração da PUC-Rio como requisito parcial para obtenção do grau de Mestre em Administração.

Orientadora: Prof. Graziela Xavier Fortunato 


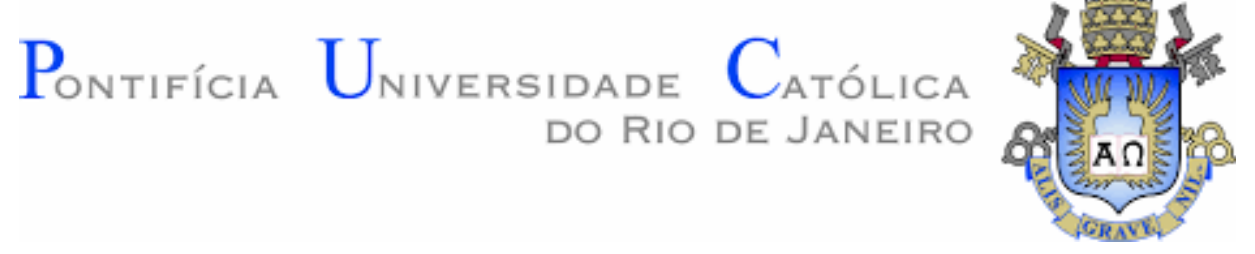

Robson Luiz Macedo

\section{AVALIAÇÃO DE MODELOS DE PRECIFICAÇÃO DE ATIVOS NO MERCADO ACIONÁRIO BRASILEIRO AÇÕES DO BANCO DO BRASIL S.A (BBAS3)}

Dissertação apresentada como requisito parcial para obtenção do grau de Mestre em Administração pelo Programa de Pósgraduação em Administração da PUC-RIO. Aprovada pela Comissão Examinadora abaixo assinada.

Prof. Graziela Xavier Fortunato

Orientadora

Departamento de Administração - PUC-Rio

Prof. Marcelo Cabus Klotzle Departamento de Administração - PUC-Rio

Prof. Carlos de Lamare Bastian Pinto

Pesquisador Autônomo

Rio de Janeiro, 24 de abril de 2019 
Todos os direitos reservados. É proibida a reprodução total ou parcial do trabalho sem autorização da universidade, do autor e da orientadora.

\section{Robson Luiz Macedo}

Graduou-se em Ciências Contábeis na UFRJ (Universidade Federal do Rio de Janeiro) em 1999. Concluiu os cursos de Pós-Graduação em Administração Econômico-financeira no CEFET-RJ (Centro Federal de Educação Tecnológica - RJ) em 2004 e Auditoria e Controladoria na UCAM (Universidade Cândido Mendes) em 2009. É funcionário concursado do Banco do Brasil desde ano de 2000, atualmente atuando na PREVI (Caixa de Previdência dos Funcionários do Banco do Brasil).

Ficha Catalográfica

Macedo, Robson Luiz

Avaliação de modelos de precificação de ativos no mercado acionário brasileiro : ações do Banco do Brasil S.A (BBAS3) / Robson Luiz Macedo ; orientadora: Graziela Xavier Fortunato. - 2019.

$61 \mathrm{f} . ; 30 \mathrm{~cm}$

Dissertação (mestrado)-Pontifícia Universidade Católica do Rio de Janeiro, Departamento de Administração, 2019.

Inclui bibliografia

1. Administração - Teses. 2. CAPM. 3. C-CAPM. 4. I-CAPM. 5. Risco. 6. Retorno. I. Fortunato, Graziela Xavier. II. Pontifícia Universidade Católica do Rio de Janeiro. Departamento de Administração. III. Título. 


\section{Agradecimentos}

Sempre estamos em busca de desafios, de situações que nos façam se superar. A escolha pelo ensino acadêmico foi o caminho que optei para desenvolver pontos que eu sentia deficiência e ampliar a forma de pensar e de analisar os questionamentos e situações da vida.

Durante essa trajetória existiram pessoas nas quais sempre estavam aptas em me ajudar, me socorrer nas emergências em qualquer horário ou em qualquer momento. Agradeço a minha esposa Claudia e meu filho Tiago por todo amor, apoio e compreensão com as minhas ausências necessárias para trilhar esse caminho; aos meus pais José Paulo e Sueli por todo amor e educação que me dispensaram; aos colegas de turma por toda ajuda na nossa trajetória; e a minha orientadora Graziela Fortunato por todo apoio e ensinamentos. 


\section{Resumo}

Macedo, Robson Luiz; Fortunato, Graziela Xavier. Avaliação de modelos de precificação de ativos no mercado acionário brasileiro - ações do Banco do Brasil S.A (BBAS3). Rio de Janeiro, 2019. 61 p. Dissertação de Mestrado - Departamento de Administração, Pontifícia Universidade Católica do Rio de Janeiro.

Este trabalho tem por objetivo analisar os retornos das ações do Banco do Brasil (BBAS3), utilizando como ferramenta os modelos do CAPM, CAPM condicional e o CAPM intertemporal no mercado acionário brasileiro, utilizando o beta estático e o dinâmico. A análise é desenvolvida através da exposição teórica das principais causas que proporcionaram o surgimento do modelo de precificação de ativos financeiros e as condições nas quais ele foi testado e desenvolvido. Foram estimados os betas estáticos e dinâmicos, sendo que os betas dinâmicos têm um maior poder de explicação sobre os excessos de retornos. Também foi constatado que os parâmetros que medem aversão a risco relativa foram significantes, indicando que um aumento de volatilidade afeta de forma significativa o retorno esperado dos agentes. Em relação aos modelos de precificação foi possível aplicar o CAPM, o CAPM condicional e o CAPM intertemporal e validar sua aplicação uma vez que as métricas apresentadas nos resultados econométricos se mostraram robustas corroborando com a literatura.

\section{Palavras-chave}

CAPM; C-CAPM; I-CAPM; Risco; Retorno. 


\section{Abstract}

Macedo, Robson Luiz; Fortunato, Graziela Xavier. Valuation of asset pricing models in the Brazilian stock market - Banco do Brasil SA shares (BBAS3). Rio de Janeiro, 2019. 61 p. Dissertação de Mestrado Departamento de Administração, Pontifícia Universidade Católica do Rio de Janeiro.

The objective of this work is to analyze the returns of Banco do Brasil's shares (BBAS3), using the CAPM models, conditional CAPM and the intertemporal CAPM in the Brazilian stock market, using static and dynamic beta. The analysis is developed through the theoretical exposition of the main causes that gave rise to the model of pricing of financial assets and the conditions under which it was tested and developed. The static and dynamic betas were estimated, and the dynamic betas have a greater power of explanation on the excesses of returns. It was also observed that the parameters that measure aversion to relative risk were significant, indicating that an increase in volatility significantly affects the expected return of the agents. Regarding the pricing models, it was possible to apply the CAPM, the conditional CAPM and the intertemporal CAPM and validate its application once the metrics presented in the econometric results were robust, corroborating with the literature.

\section{Keywords}

CAPM; C-CAPM; I-CAPM; Risk; Return. 


\section{Sumário}

1. Introdução

2. Revisão de literatura 14

2.1 Modelos alternativos de precificação de ativos do CAPM 14

3. Metodologia de aplicação do modelo de precificação de ativos CAPM

3.1 Fonte de dados e amostra 25

3.2 Descrição dos modelos econométricos aplicados 29

$\begin{array}{lll}3.2 .1 & \text { CAPM } & 29\end{array}$

$\begin{array}{ll}3.2 .2 \text { CAPM Conditional } & 31\end{array}$

3.3 Variáveis utilizadas 34

$\begin{array}{lll}3.4 & \text { Testes de robustez realizados } & 37\end{array}$

4. Análise dos resultados 38

4.1 Estatísticas descritivas e testes de raiz unitária 38

4.2 Teste com o modelo CAPM para beta estático 40

4.3 Teste com o modelo de CAPM para beta dinâmico 42

4.4 Apresentação do resultado dos modelos 46

4.4.1 CAPM 46

4.4.2 CAPM Conditional 47

$\begin{array}{ll}\text { 4.4.3 CAPM Intertemporal } & 47\end{array}$

5. Considerações finais 49

6. Referências bibliográficas 51

Anexo I - série histórica da cotação das ações do Banco do Brasil 56 anexo II - estimativas e resíduo do modelo estrutural utilizado para a estimação do beta dinâmico estrutural 61 


\section{Lista de figuras}

Figura 1 - Linha do tempo / Governança do BB 26

Figura 2 - Composição acionária e geração de valor do BB 26

Figura 3 - Quadro Comparativo 28 


\section{Lista de tabelas}

Tabela 1 - Artigos sobre o modelo de precificação de ativos e suas aplicações

Tabela 2 - Estatísticas descritivas dos excessos de retorno do ativo BBAS3

Tabela 3 - Estatística calculada pelos testes de raiz unitária ADF e KPSS

Tabela 4 - Modelo CAPM com o beta estático 40

Tabela 5 - Diagnóstico dos resíduos 41

Tabela 6 - Estimativa da equação do beta estático 41

Tabela 7 - Modelo MGARCH DCC 43

Tabela 8 - Diagnóstico dos resíduos MGARCH 43

Tabela 9 - Betas dinâmicos médios 44

Tabela 10 - Estimativa da equação dos excessos de retornos cross section com betas condicionais 44

Tabela 11 - Estimativa da equação dos excessos de retorno cross section com betas estruturais $\quad 45$

Tabela 12 - Resumo dos resultados estatísticos do modelo CAPM $\quad 46$

Tabela 13 - Resumo dos resultados estatísticos do modelo CAPM Condicional 47

Tabela 14 - Resumo dos resultados estatísticos do modelo CAPM Intertemporal 48

Tabela 15- Estimativa da variância Modelo Estrutural 61

Tabela 16- Diagnóstico dos resíduos do modelo estrutural 61 
As montanhas da vida não existem apenas para que você chegue ao topo, mas para que você aprenda o valor da escalada.

(Autor desconhecido) 


\section{INTRODUÇÃO}

O processo de globalização dos investimentos consiste em um desafio para os modelos de precificação de ativos, tendo em vista a exposição ao risco, inerente ao país no qual é realizado o investimento (Fallet, 2016).

Em finanças, considera-se que a melhor forma de aumentar o valor da empresa é aprimorando as decisões de investimentos, financiamentos e distribuição de dividendos. Na gestão de carteiras, procura-se encontrar papéis negociados por um valor inferior ao seu valor real para, em seguida, ter-se uma perspectiva de geração de lucros na convergência de preços e valor justo. Para saber se os mercados são eficientes, analisam a convergência dos preços dos ativos ao valor justo, considerando seus desvios e a rapidez desse movimento. Entender os determinantes do valor justo, portanto é um pré-requisito para a realização de decisões financeiras acertadas (Damodaran, 2006).

Dentro do contexto do mercado de finanças, este trabalho tem como foco a busca por um melhor entendimento sobre o retorno das ações do Banco do Brasil, denominadas de BBAS3, no período de 1998 a 2018.

O Banco do Brasil é um dos bancos mais antigos do Brasil, tendo 200 anos de existência, e com uma presença global em dezesseis países em todo mundo, e tendo realizado a primeira oferta pública de suas ações em 1906.

As ações do Banco do Brasil merecem atenção especial porque sofrem forte influência das decisões do governo, tendo em vista que o banco é de economia mista, e o governo tem a maior participação em sua gestão, algo em torno de $53 \%$. O período escolhido se justifica em função das oscilações apresentadas, pois a partir de 1999 houve uma ascensão nos preços das ações do banco, sofrendo uma ruptura em 2008 e passando oito anos em oscilações de altas e quedas, retomando a partir de 2016 a ascensão em seu preço que se perdura atualmente.

As ações do Banco do Brasil possuem uma peculiaridade dentre os demais tipos de ações, pois são afetadas tanto pelo risco sistemático como pelo não sistemático. A taxa de juros é o elemento principal desta particularidade característica.

Os modelos de precificação de ativos foram as ferramentas escolhidas para avaliar o retorno das ações do BBAS3, levando em consideração um importante fator, como já mencionado, a taxa de juros. 
Dentre os modelos de precificação de ativos destaca-se o Capital Asset Pricing Model (CAPM) ou Modelo de Precificação de Ativos de Capital, desenvolvido por Sharpe (1964), Lintner (1965) e Mossin (1966), que proporciona a determinação do retorno em função do risco sistemático presente nos ativos financeiros, partindo do pressuposto de mercado eficiente.

Assim, pode-se inferir que a precificação de ativos tem sido amplamente discutida em função de sua relevância nas decisões de alocação de recursos, principalmente por considerar a relação entre o risco e o retorno requerido. Através dos modelos de precificação de ativos, o custo de capital é determinado e projetos de viabilidade de investimentos são analisados em relação a tal variável. Dessa forma, ressalta-se a importância dos modelos de precificação de ativos.

Assim, define-se como problema de pesquisa: Qual modelo alternativo de precificação de ativos ( CAPM, CAPM Condicional - CCAPM e CAPM Intertemporal - ICAPM) pode ser utilizado como ferramenta na análise do comportamento das ações do Banco do Brasil, considerando o efeito que a taxa de juros exerce tanto sobre o desempenho do banco como sobre o valor das ações?

Para Blank et al (2014), o CAPM condicional busca verificar se o modelo é capaz de melhor explicar os retornos dos ativos ao se considerar variação temporal nos momentos condicionais.

Machado et al (2013) em seu trabalho, destaca que o CAPM intertemporal prevê que o prêmio de risco de um ativo dependerá não apenas da covariância de sua taxa de retorno no mercado de portfólio, mas também em covariância com variáveis de estado.

Segundo Costa et al (2016), pesquisar e analisar o comportamento dos preços dos ativos financeiros permanece um anseio em diversos estudos. A pioneira análise de Markowitz (1952) desencadeou uma linha de pensamento que propunha a mensuração do risco de ativos a partir do retorno esperado e sua variância. Porém, a difícil aplicabilidade inerente ao cálculo das covariâncias entre os ativos individuais motivou Sharpe (1964), Lintner (1965) e Mossin (1966) a desenvolverem o Capital Asset Pricing Model (CAPM) que relaciona o retorno esperado de um ativo ao seu risco não diversificável e ao retorno do ativo livre de 
risco, enquanto o risco idiossincrático é tratado no CAPM como aquele que pode ser diversificado.

O presente estudo buscará contribuir com testes empíricos com vista a identificar dentre os modelos alternativos de precificação de ativos, qual pode ser utilizado como ferramenta de análise de ações para o mercado de finanças no Brasil. $\mathrm{Na}$ maioria dos estudos, o que se busca é fornecer uma análise critica dos modelos alternativos do CAPM, mas este não será o foco neste trabalho. A colaboração acadêmica é percebida à medida que praticamente não existe estudo com tal foco, e identificando que a maioria dos estudos busca explicações no CAPM, porém para este estudo, modelos alternativos do CAPM serão testados, dentre os quais se destacam: CAPM Intertemporal e $o$ CAPM Conditional.

O trabalho será estruturado em cinco capítulos, distribuídos da seguinte maneira:; no capítulo 2 é apresentada a realizada uma revisão de literatura sobre os modelos alternativos do CAPM, abordando ainda aspectos relacionados com a comparação e crítica aos modelos e artigos mais recentes sobre avaliação de ações e modelos alternativos. O capítulo 3 apresenta a metodologia, com coleta e tratamento dos dados, além dos modelos aplicados. O capítulo 4 analisa-se os resultados apresentados, destacando a eficiência dos modelos; e por fim no capítulo 5 são apresentadas as considerações finais e sugestões para futuros trabalhos. 


\section{REVISÃO DE LITERATURA}

\subsection{Modelos alternativos de precificação de ativos do CAPM}

Estrada (2000) desenvolveu um modelo para substituir o tradicional CAPM. Esse modelo foi batizado de Downside Capital Asset Pricing Model (D-CAPM). O que difere o modelo criado por Estrada do convencional CAPM é a medida de sensibilidade, que aqui é denominada downside beta.

Segundo Lucena e Motta (2004), o D-CAPM, proposto por Estrada (2002), incorpora basicamente os mesmos pressupostos do CAPM original, com a diferença de que seu coeficiente de risco só considera como relevante para estudo a parte negativa dos retornos, considerada pelos analistas realmente como risco de perda. Esta afirmação realmente faz sentido na medida em que risco é conceituado como a possibilidade de perda financeira.

O D-CAPM pode ser calculado pela razão entre o semidesvio dos retornos do ativo e o semidesvio dos retornos do mercado, ou seja, pela co-semivariância dividida pela semivariância dos retornos do mercado.

De acordo com ESTRADA (2000), essa medida de downside risk possui um maior poder de explicação dos retornos dos ativos em mercados emergentes que o tradicional beta do CAPM.

Segundo Elton et al. (2003), o D-CAPM é um modelo que centra seu foco unicamente no risco não desejado, ou seja, analisa apenas os retornos que estão abaixo do retorno esperado (desvio negativo), pois, de acordo com Estrada (2000), os investidores se preocupam apenas com a parte negativa do risco, uma vez que esta é indesejável para os investidores.

Sendo assim, o D-CAPM consegue estimar melhor o retorno que o investidor efetivamente espera por estar investindo seu capital em ativos de um país emergente. O cálculo do retorno esperado pelo D-CAPM é dado pela seguinte fórmula: 
$r_{i}=r_{f}+\left(r_{M}-r_{f}\right) B^{D}$

em que :

$B^{D}=$ downside beta.

Onde:

$$
B^{D}=\frac{E\left\{\operatorname{Min}\left[\left(r_{i}-r_{i}\right), 0\right] \cdot \operatorname{Min}\left[\left(r_{M}-r_{M}\right), 0\right]\right\}}{E\left\{\operatorname{Min}\left[\left(r_{M}-r_{M}\right), 0\right]^{2}\right\}}
$$

Sendo:

$$
\begin{aligned}
& E\left\{\operatorname{Min}\left[\left(r_{i}-r_{i}\right), 0\right] \cdot \operatorname{Min}\left[\left(r_{M}-r_{M}\right), 0\right]\right\}=\text { co-semivariância } \\
& E\left\{\operatorname{Min}\left[\left(r_{M}-r_{M}\right), 0\right]^{2}\right\}=\text { semivariância }
\end{aligned}
$$

De acordo com Lucena e Motta (2004), o modelo desenvolvido por Estrada (2002) quis fornecer uma nova metodologia, excluindo o que muitos não consideram como risco, que á a parte positiva da volatilidade dos retornos. O autor chegou a resultados estatisticamente mais significativos do que a relação linear proposta pelo CAPM tradicional para países emergentes, o que supostamente poderia sugerir uma modelagem mais adequada. Foram utilizados os mesmos coeficientes de risco que apresentaremos a seguir, e quando colocados conjuntamente em uma mesma regressão, apenas o downside beta foi considerado como significante. Os resultados encontrados também mostram que o novo coeficiente de risco proposto é mais conservador que o beta do CAPM tradicional. O retorno exigido é maior em torno de $2,5 \%$ em média.

De acordo com Carassini (2017), a origem do modelo Conditional Capital Asset Pricing Model ou CCAPM condicional, é em função do modelo CAPM tradicional que não considera a variação dos betas dos ativos ao longo do tempo. 
Segundo Tambosi Filho et al apud Carassini (2017), a principal variação do modelo CCAPM está relacionada ao risco sistemático ao longo do tempo, o qual não e estável, representado pela variação dos betas ao longo do tempo, corrigindo o problema principal do CAPM original, que era estático e não dinâmico, como se constata no mercado real.

Garcia (2015) destaca que o CCAPM é um modelo propõe que os investidores consumiam toda sua riqueza depois de um período, de forma que a riqueza e o consumo acabavam se confundindo. Em essência era necessário traçar um plano de consumo, sendo que o investidor deverá fazer um balanceamento entre a alocação do patrimônio, analisando as possibilidades de consumir hoje, poupar e investir buscando compor um montante sabendo que terá um consumo futuro. Portanto a disponibilidade de ativos com maior grau de risco e consequente maior crescimento esperado seria uma oportunidade viável para aquele investidor que busca, fazendo com que o investidor analise as opções de alocar parte do dinheiro poupado em títulos de risco.

O modelo do CAPM condicional, de acordo com Jagannathan e Wang (1996), pode ser representado na equação abaixo, como segue:

$$
E\left[R_{i t} / I_{t-1}\right]=g_{0 t-1}+g_{1 t-1} b_{i t-1}
$$

Onde: $\mathrm{I}_{t-1}$ é o nível de informação dos investidores no final do periodo $t-1 \mathrm{e}$ $\mathrm{b}_{i t-1}=$ é o beta condicional do ativo $i$ no período $t-1$ definido como:

$$
b_{i t-1}=\operatorname{Cov}\left(R_{i t}, R_{m t} / I_{t-1}\right) / \operatorname{Var}\left(R_{m t} / I_{t-1}\right)
$$

Sendo ainda: $g_{0 t-1}$ é o retorno esperado condicional sobre o portfólio com beta igual a zero e $g_{1 t-1}$ é o prêmio do risco de mercado condiocional. 
De acordo com Carassini (1997), no CCAPM as informações no tempo correspondente, são importantes, pois os betas tanto dos ativos, como do preço do risco, variam no tempo da tomada da informação.

Segundo Jagannathan e Wang apud Carassini (1997), em seu trabalho empírico assumem que o beta de cada ação e o prêmio de risco de mercado varia ao longo do tempo. Eles se baseiam na metodologia de Fama e MacBeth (1974).

Segundo Almeida (2010), o modelo intertemporal de apreçamento de ativos de capitais de Merton (1973), em inglês, Intertemporal Capital Asset Pricing Model (ICAPM), supõe que existe variação estocástica no conjunto de oportunidades de investimento, sugerindo que provavelmente exista prêmio de risco associado com inovações nas variáveis de estado descritas nas oportunidades de investimento. No modelo de Merton (1973) os fatores que explicam o retorno de um ativo $i$ qualquer são variáveis de estado que preveem mudanças na distribuição dos retornos ou renda futuros.

Para Machado et al (2011), o ICAPM de Merton (1973) parte de um problema de maximização da utilidade do consumo intertemporal num ambiente em que os ativos são negociados em tempo contínuo. Resolvendo o problema dinâmico, é possível encontrar a função de demanda por ativos e a equação de precificação no equilíbrio.

De acordo com Bali e Engle (2010), pode-se escrever a equação de precificação de forma discreta como:

$$
E_{t}\left(R_{t+1}\right)-r_{t}^{f}=A \quad \operatorname{Covt}\left(R_{t+1}, R^{m_{t+1}}\right)+\operatorname{Covt}\left(R_{t+1}, Z_{t+1}^{\prime}\right) B
$$

Onde:

$E_{t}\left(R_{t+1}\right)$ é o vetor $(n \times 1)$ de retornos esperados de um determinado portfólio formado por " $n$ " ativos na data $\mathrm{t}+1$;

$\mathrm{r}_{\mathrm{t}}^{\mathrm{f}}$ é o vetor ( $\left.\mathrm{n} \times 1\right)$ que contém o retorno do ativo livre de risco;

A é um escalar e representa o coeficiente de aversão ao risco dos investidores; $\mathrm{r}_{\mathrm{t}+1}$ é o retorno da carteira de mercado na data $\mathrm{t}+1$; 
$\operatorname{Covt}\left(\mathrm{R}_{\mathrm{t}+1}, \mathrm{R}_{\mathrm{t}+1}\right)$ é um vetor ( $\left.\mathrm{n} \times 1\right)$ que contém a covariância condicional no instante t entre o vetor de retornos dos "n" ativos e o retorno da carteira de mercado na data $\mathrm{t}+1$

$\mathrm{Z}_{\mathrm{t}+1}$ é um vetor $(\mathrm{k} \times 1)$ que contém todas as variáveis de estado responsáveis por causar mudanças no conjunto de oportunidades de investimento na data $t+1$

$\operatorname{Covt}\left(R_{t+1}, Z_{t+1}^{\prime}\right)$ é uma matriz ( $\mathrm{x} k$ ) em que cada coluna contém o vetor de covariâncias condicionais no instante $t$ entre o vetor de retornos e determinada variável de estado. Ou seja, a primeira coluna dessa matriz é um vetor de covariâncias entre os ativos do portfólio e a primeira variável de estado utilizada, que é o primeiro elemento de $Z_{t+1}$, e assim por diante para as demais colunas dessa matriz;

B é um vetor ( $\mathrm{k}$ x 1) em que o j-ésimo elemento representa o coeficiente de sensibilidade do portfólio em relação à j-ésima variável de estado.

Ao se considerar a equação (5), infere-se que o investidor deve ser remunerado não só pelo risco sistemático da carteira de mercado, mas também pelo risco de que mudanças desfavoráveis no conjunto de oportunidades de investimento venham a ocorrer, conforme destacado por Machado et al (2011).

Nielsen e Vassalou (2006) demonstram formalmente que as variáveis: taxa real de juros e o máximo índice de Sharpe, além da riqueza, precificam o ICAPM. Eles concluem que os investidores somente fazem hedge contra mudanças nas médias, variâncias e covariâncias de retornos dos ativos que afetam a posição ou a inclinação da fronteira eficiente geral de investimento.

De acordo com Fama e French (2007), o modelo ICAPM parte de uma premissa diferente a respeito dos objetivos dos investidores. Os investidores do ICAPM preferem um elevado retorno, porém também estão preocupados com as covariâncias do retorno da carteira em relação a variáveis de estado. Desta maneira, as carteiras ótimas são "multifatorialmente eficientes", o que significa que têm os mais elevados retornos esperados possíveis, dando as variâncias de seus retornos e as covariâncias de seus retornos em relação às variáveis de estado relevantes. 
Segundo Araújo et al (2012), o modelo CAPM passou a ser alvo de inúmeros testes empíricos por parte dos pesquisadores, a fim de avaliar sua validade prática. Com a constatação de algumas de suas anomalias (deficiências) a partir destes testes, a sua efetividade passou a ser questionada, visto que o poder explicativo do modelo não se mostrava satisfatório frente às análises. Isso levou os pesquisadores em contabilidade e finanças a buscarem soluções que ampliassem o fator explicativo do CAPM, o que resultou no surgimento de algumas variantes como o CCAPM (conditional) e o DCAPM (downside), entre outros, abarcando um maior número de variáveis e com melhor adequação aos pressupostos, tendo em vista a característica de cada mercado, o que permitia o aumento da eficiência de seu poder de explicação.

De acordo com Rochman e Eid Jr. (2006) e Silva e Munhoz (2006), o modelo CAPM foi considerado efetivo para mensuração do risco e na estimativa do risco de fundos.

Porém Tambosi Filho, Costa Jr. e Rosseto (2006) consideraram o C-CAPM mais eficiente nas previsões do que o CAPM. Para Castro Silva, Melo e Pinto (2009), o C-CAPM foi ligeiramente mais estável, e a presença de mudanças estruturais nas séries históricas estudadas apontaram que o beta não é o único fator que explicaria o risco. Em Castro Silva et al (2009) ficou evidenciado a maior eficiência do C-CAPM por apresentar menores critérios de informações de Akaike e Schwarz, sem a presença de quebra estrutural.

Em relação ao D-CAPM, Motta, Fortunato e Russo (2007), consideraram o modelo pouco adequado para estimar o custo do capital próprio no Brasil.

De acordo com Fama e French (2007), no CAPM, os investidores só se preocupam com a riqueza que sua carteira produz ao fim do período em andamento. No I-CAPM, os investidores se importam não só com o payoff ao fim do período, mas, também, com as oportunidades que terão de consumir ou investir esse payoff. As críticas ao modelo CAPM giram em torno da relação entre o coeficiente beta e o retorno esperado, fazendo com que questionamentos como: O CAPM funciona? $\mathrm{O}$ beta constitui um bom substituto para o risco e está correlacionado aos retornos esperados? 
De acordo com Damodaran (1999), uma das críticas que podem ser realizadas em relação ao modelo CAPM está relacionada com diversificação da carteira e com consequência do risco. $\mathrm{O}$ argumento de que a diversificação reduz o risco seja incontestável, a premissa, adotada pelo CAPM, de que o risco diversificável não importa, não o é. Ela é baseada na pressuposição de que o investidor marginal no mercado, que fixa os preços e, portanto, determina o enfoque dado ao risco, é bastante diversificado e espera ser recompensando apenas em função do risco não diversificável. Se o investidor marginal não estiver diversificado, o risco diversificável poderá afetar preços e retornos esperados.

Em consequência das inúmeras críticas ao modelo CAPM, surgiu um modelo alternativo de precificação de ativos denominado Arbitrage Pricing Model (APT), que possui uma lógica semelhante ao do CAPM, ou seja, investidores são recompensados por assumir riscos não diversificáveis. A diferença básica entre os dois modelos está no fato do CAPM considerar que somente um fator (sensibilidade em relação à carteira de mercado) absorve o risco não diversificável, enquanto que no APT podem ser considerados múltiplos fatores. O número e a identidade dos fatores, são determinados pelos dados sobre retornos históricos.

Segundo Roll (1997), no trabalho intitulado de “Crítica de Roll”, uma crítica atribuída ao modelo CAPM é sua impossibilidade de ser testado empiricamente, pois existe a impossibilidade de se observar o portfólio de mercado, sendo que nenhum teste já feito anteriormente foi realmente um teste da teoria do CAPM de Sharpe (1964), mas sim, testes considerando a hipótese de que o portfólio de mercado é eficiente.

De forma complementar, Roll (1977), afirma que o modelo de precificação de ativos financeiros só pode ser testado, caso se obtenha a composição exata da carteira de mercado, sendo que nesta situação, sugere que a teoria seria testável, porém, somente se todos os ativos individuais fossem incluídos na amostragem.

Conforme destacado por vários autores como Stambaugh (1982); Costa Jr. (1996); Roll (1977), o CAPM não condicional ou estático, considera que o mercado está em equilíbrio, sem variações e com isto, estabelece o preço do risco de mercado 
e também, a relação entre risco e retorno esperado ou desejado. Sendo está afirmação um dos pontos de crítica ao modelo.

Silva et al apud Minardi (2012) discorre acerca de um dos principais aspectos que geram críticas e dificuldades nas estimações do capital próprio no Brasil, ou seja, a utilização de retornos passados na previsão dos futuros. De acordo com a autora, a eficiência de mercado exerce uma grande influência no retorno apresentado no decorrer dos anos, de maneira que "se os mercados tiverem um alto grau de eficiência, o preço de mercado de um título incorpora as informações correntes adequadamente, e é a melhor estimativa de seu valor intrínseco". Em sua pesquisa, apesar do mercado brasileiro ser um tanto instável, foi verificado que existe certo grau de previsibilidade se utilizados dados baseados no Índice Brasil (IBRX), ou seja, índice Brasil, no lugar do IBOVESPA.

Em relação às críticas ao I-CAPM, Harvey (1995) altera a sua posição e rejeita até certo ponto o I-CAPM enquanto modelo de avaliação global, considerando que este modelo explica de forma deficiente os retornos anormais obtidos nos mercados acionistas dos países emergentes. Harvey expõe essa deficiência ao afirmar que os mercados emergentes eram mais segmentados relativamente ao mercado global, não se verificando, assim, o pressuposto básico do modelo de integração de mercados.

Reiganum (1981) documenta anomalias empíricas que sugerem que o CAPM é mal especificado ou que os mercados de capitais não são eficientes. Foi observado que carteiras com base no tamanho da empresa ou na razão entre lucro e preço apresentam retornos médios sistematicamente diferentes daqueles previstos pelo CAPM. Há persistência de pelo menos dois anos nos retornos "anormais", o que reduz a probabilidade de que estes resultados sejam gerados por uma ineficiência do mercado.

Embora existam críticas ao CAPM, Benson e Faff (2012) afirmam que tais críticas estão relacionadas ao fato de que muitos estudos empíricos são naturalmente voltados para testes de curto prazo, podendo produzir resultados inconsistentes ou mesmo contrários às predições do modelo. Dessa forma, os autores constatam que o CAPM é um modelo de equilíbrio e que o conceito de 
equilíbrio é irrealista no curto prazo, funcionando muito melhor no longo prazo. A precificação de ativos deve ser considerada uma preocupação de longo prazo.

Lucena e Motta (2004) expõem que um dos métodos mais recentes destinado a corrigir as imperfeições do modelo tradicional é o método sugerido e aplicado por Estrada (2002a, apud Lucena; Motta, 2004) e Estrada (2002b, apud Lucena; Motta, 2004), o qual foi utilizado no estudo realizado por Lucena e Motta (2004). Porém, embora constitua uma forma diferenciada de avaliação, o modelo não se mostrou eficaz ao ser inserido no mercado brasileiro. Assim, embora existam diversos modelos alternativos, até o momento o CAPM ainda permanece como sendo o mais usual.

Um importante ponto a ser observado está relacionado com artigos e estudos que foram selecionados na elaboração deste trabalho, e que demonstram como o tema vem sendo desenvolvido e abordado, o período analisado foi de 2002 a 2017. A Tabela 1 apresenta estes artigos, bem como o ano em que foram elaborados e seus objetivos para com o tema. 
Tabela 1: Artigos sobre modelo de precificação de ativos e suas aplicações.

\begin{tabular}{|c|c|c|c|}
\hline $\begin{array}{l}\text { Ano do } \\
\text { Trabalho }\end{array}$ & Autor & Titulo & Objetivo do trabalho \\
\hline 2002 & Zandavalli & $\begin{array}{c}\text { Capital Asset Price Model (CAPM): } \\
\text { uma aplicação ao mercado de ações } \\
\text { brasileiro }\end{array}$ & $\begin{array}{l}\text { Este trabalho tem por objetivo apresentar a fundamentação } \\
\text { teórica e efetuar uma aplicação prática de uma das mais } \\
\text { importantes descobertas no campo das finanças: o modelo de } \\
\text { precificação de ativos de capital padrão, o CAPM. Foram } \\
\text { analisadas cinco ações com a maior participação relativa na } \\
\text { carteira teórica do IBOVESPA e com retornos publicados. }\end{array}$ \\
\hline 2007 & Alves & $\begin{array}{c}\text { Análise comparativa e teste empírico } \\
\text { da validade dos modelo CAPM } \\
\text { tradicional e condicional: o caso das } \\
\text { ações da Petrobrás }\end{array}$ & $\begin{array}{l}\text { O objetivo deste artigo é fazer uma análise comparativa e testar } \\
\text { empiricamente a validade dos modelos CAPM tradicional e } \\
\text { condicional utilizando as ações preferenciais da Petrobrás. A } \\
\text { metodologia empregada foi a de estimar primeiramente o modelo } \\
\text { CAPM tradicional, através do método dos mínimos quadrados } \\
\text { ordinários e, posteriormente estimou-se o modelo condicional, } \\
\text { chamado também de GARCH-M. }\end{array}$ \\
\hline 2009 & Barbosa & $\begin{array}{c}\text { Análise Comparativa dos modelos } \\
\text { CAPM tradicional e condicional: um } \\
\text { estudo de caso do clube de } \\
\text { investimentos AIVALE }\end{array}$ & $\begin{array}{l}\text { Avaliar o risco de mercado e estimar o beta do Clube de } \\
\text { Investimento (AIVALE), por meio do uso do Capital Asset } \\
\text { Pricing Model (CAPM), foi feita uma análise comparativa e } \\
\text { testes empíricos para avaliar duas técnicas de precificação de } \\
\text { ativos, o CAPM tradicional o o CAPM Condicional. }\end{array}$ \\
\hline 2010 & Almeida & $\begin{array}{c}\text { Estimação do CAPM Intertemporal } \\
\text { com ações da Bovespa }\end{array}$ & $\begin{array}{l}\text { Estimar um modelo de apreçamento de ativos de capital } \\
\text { financeiro intertemporal, em inglês, intertemporal capital asset } \\
\text { pricing model - ICAPM, utilizando as inovações produzidas de } \\
\text { duas variáveis de estado: o índice máximo de Sharpe e a taxa } \\
\text { real de juros. }\end{array}$ \\
\hline 2012 & Godeiro & conditionalcorrelations & $\begin{array}{l}\text { A pesquisa objetiva testar o CAPM para o mercado de ações } \\
\text { brasileiro utilizando o beta estático e o beta dinâmico. A } \\
\text { amostra utilizada é composta por } 28 \text { ações do índice Ibovespa } \\
\text { em vinte de março de } 2012 \text { e que foram negociados durante todo } \\
\text { o período pesquisado, que vai de } 01 / 01 / 1995 \text { a } 20 / 03 / 2012 \text {. }\end{array}$ \\
\hline 2015 & Garcia & $\begin{array}{c}\text { Aplicação do CAPM condicional ao } \\
\text { mercado acionário brasileiro }\end{array}$ & $\begin{array}{l}\text { Este trabalho tem por objetivo testar empiricamente o modelo do } \\
\text { CAPM condicional no mercado acionário brasileiro. A análise é } \\
\text { desenvolvida através da exposição teórica das principais } \\
\text { causas que proporcionaram o surgimento do modelo de } \\
\text { precificação de ativos financeiros e as condições nas quais ele } \\
\text { foi testado e desenvolvido. }\end{array}$ \\
\hline 2016 & Fellet & $\begin{array}{l}\text { Avaliação de modelos de } \\
\text { precificação de ativos no mercado } \\
\text { acionário brasileiro }\end{array}$ & $\begin{array}{l}\text { Testar e avaliar modelos de precificação de ações no mercado } \\
\text { acionário brasileiro, aplicando-os às ações negociadas na Bolsa } \\
\text { de Valores de São Paulo e identificando dentre os modelos } \\
\text { testados aquele(s) que apresenta(m) desempenho } \\
\text { superior,sendo eles: CAPM, CAPM Global, CAPM Local, APT } \\
\text { e Modelo de } 3 \text { Fatores. }\end{array}$ \\
\hline 2016 & Caldas & $\begin{array}{c}\text { Uma análise preditiva da Volatilidade } \\
\text { dos índices PETR3, BBAS3, BBDC3, } \\
\text { BTOW3, IBOVESPA e de suas taxas } \\
\text { de Correlação, utilizando modelos da } \\
\text { família ARCH e VaR. }\end{array}$ & 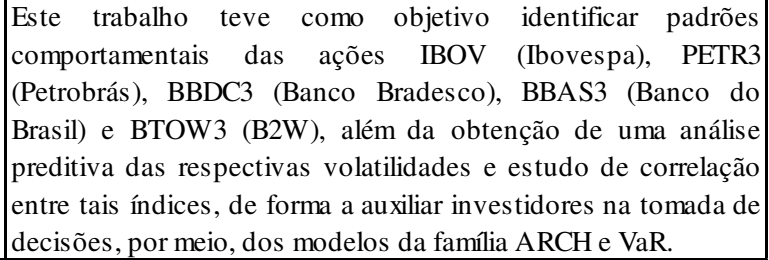 \\
\hline 2017 & Costa et al & $\begin{array}{c}\text { Um estudo empírico da dinâmica da } \\
\text { correlação do retorno das ações do } \\
\text { Brasil }\end{array}$ & $\begin{array}{l}\text { Examinar empiricamente o comportamento da correla }{ }_{s} \mathrm{c}^{\sim} \text { ao } \\
\text { entre o retorno de as c }{ }^{2} \text { oes listadas na BMF\& BOVESPA no } \\
\text { per'1odo de } 2000 \text { a 2015. Para tanto, utilizamos modelos GARCH } \\
\text { multivariados. }\end{array}$ \\
\hline
\end{tabular}

Fonte: Elaboração própria. 
Os artigos e estudos analisados têm como foco os modelos como CAPM tradicional, CAPM condicional, CAPM intertemporal e suas aplicações em mercados acionários ou com determinadas ações ou carteiras, desta maneira, o tema para o presente trabalho foi elaborado utilizando os modelos como ferramenta de análise dos retornos das ações do Banco do Brasil, que representam o objeto em estudo neste trabalho. 


\section{METODOLOGIA DE APLICAÇÃO DO MODELO DE PRECIFICAÇÃO DE ATIVOS - CAPM}

Este capítulo seguirá a ordem de desenvolvimento de metodologias sendo a seção 3.1 a apresentação da fonte de dados e da amostra a ser analisada; a seção 3.2 aborda as variáveis a serem utilizadas na modelagem; a seção 3.3 apresenta a descrição dos modelos econométricos a serem aplicados aos modelos de precificação dos ativos e por fim, a seção 3.4 identifica os testes de robustez a serem realizados para verificação dos modelos.

\subsection{Fonte de dados e Amostra}

O Banco do Brasil S.A (BB) é uma instituição financeira brasileira, constituída na forma de sociedade de economia mista, com participação do governo federal do Brasil em 53\% das ações. O Banco foi fundado em 1808 e foi a primeiras empresa listada em bolsa de valores no Brasil.

O BB tem como visão proporcionar a melhor experiência de vida das pessoas e promover o desenvolvimento da sociedade, de forma inovadora, eficiente e sustentável. O banco tem como valores a ética, a inovação, a eficiência, a confiabilidade e o espírito público entre outros, e tem como propósito estar o mais próximo das pessoas e ajudar a preservar o que é importante para os clientes, acionistas, funcionários e toda sociedade.

Os segmentos nos quais o BB atua são: bancário, investimentos, gestão de recursos, seguridade, meios de pagamento entre outros segmentos.

A Figura 1 apresenta a linha do tempo da evolução da governança do banco e a Figura 2 apresenta a composição acionária e geração de valor do BB. 


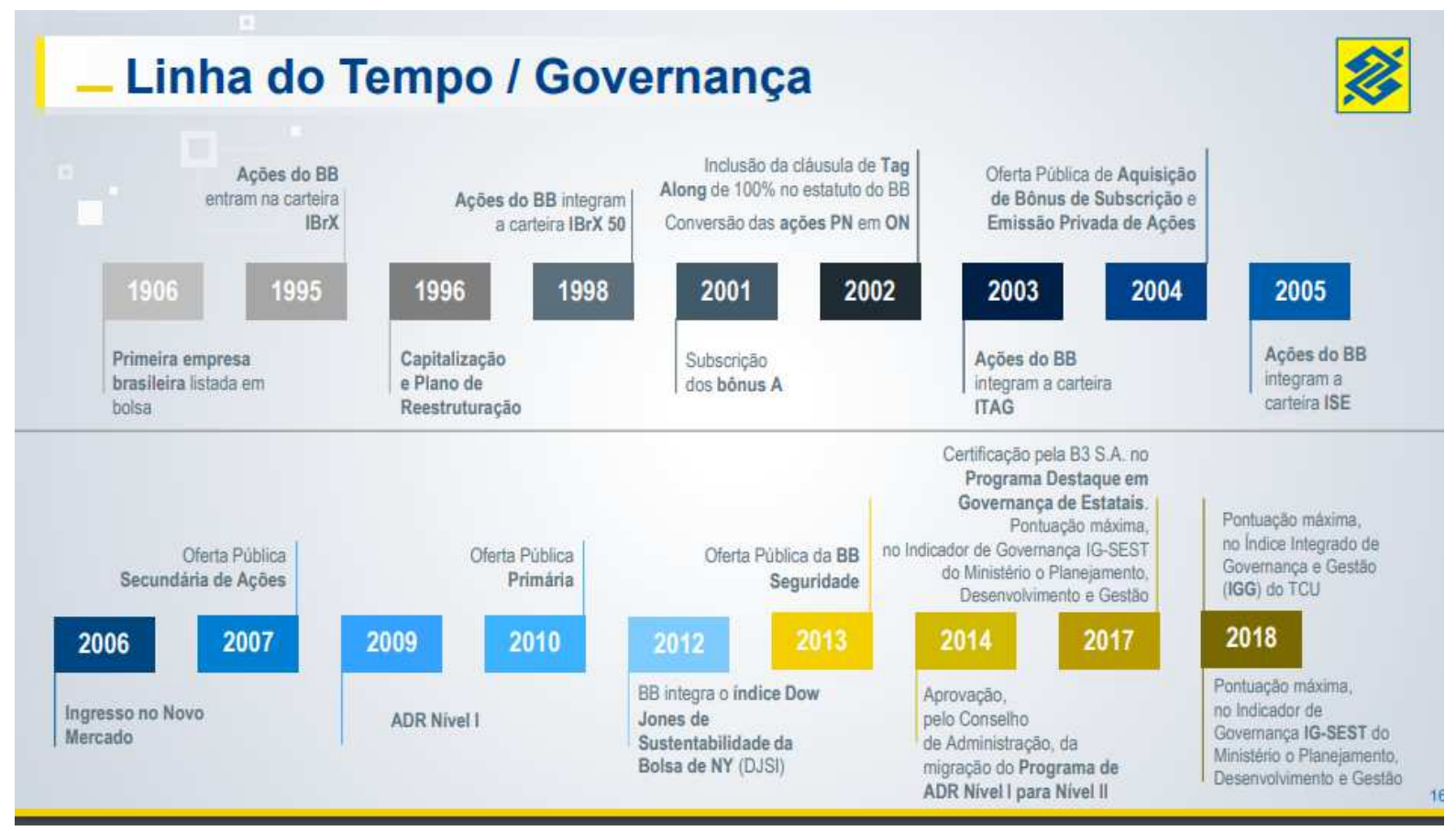

Figura 1: Linha do tempo / Governança do BB.

Fonte: Apresentação institucional 3T8 / Banco do Brasil (2018).

\section{- Composição Acionária e Geração de Valor}

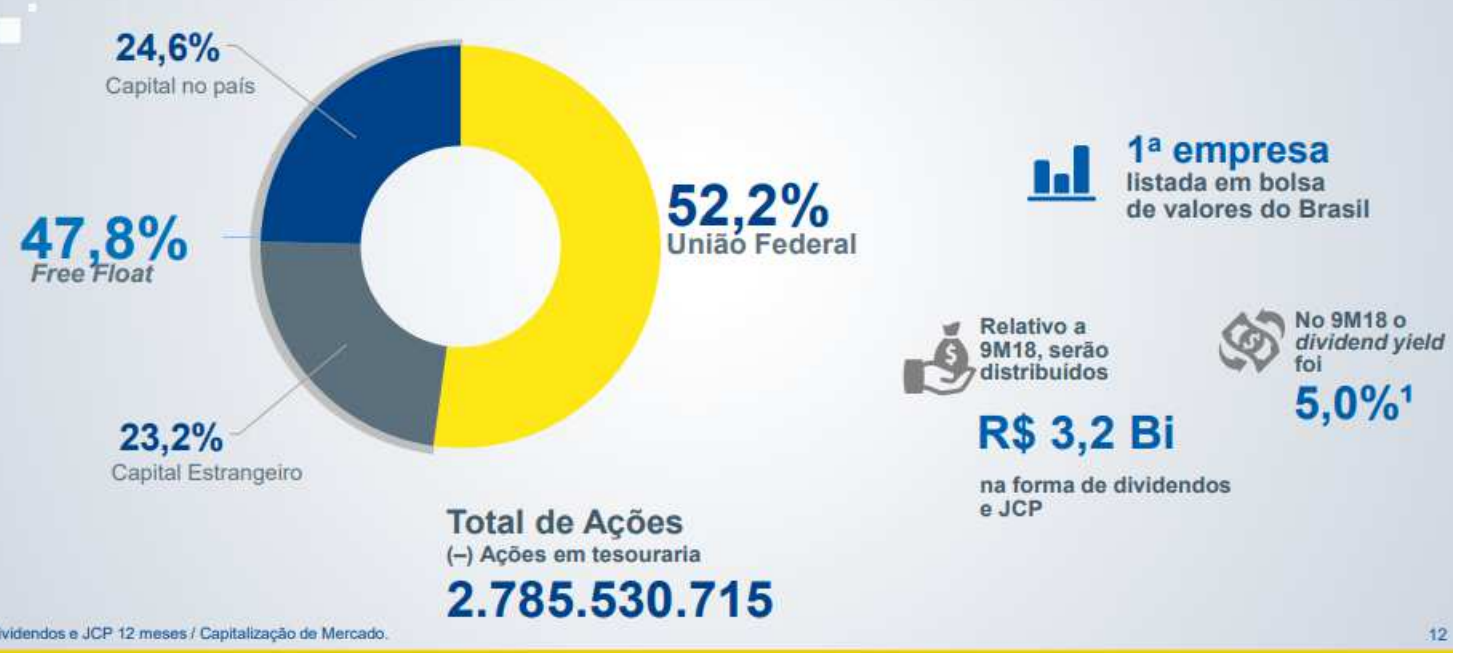

Figura 2: Composição acionária e geração de valor do BB.

Fonte: Apresentação institucional 3T8 / Banco do Brasil (2018). 
O BB é considerado um dos cinco maiores bancos do país, segundo estudo realizado pelo portal Economática, em 2018, mostra que o Itaú Unibanco (ITUB4), atualmente é o maior banco por valor de mercado do país, seguido pelo Bradesco (BBDC4), Banco do Brasil (BBSA3) e por fim, o Santander (SANB11). Segundo Pavini (2018), o valor de mercado do Itaú Unibanco, de R 313 bilhões, é quase três vezes o do Banco do Brasil, apesar de o banco estatal ter quase o mesmo volume de ativos. Em 2017, o total de ativos do Itaú era de R \$ 1,503 trilhão, enquanto o do $\mathrm{BB}$ era de $\mathrm{R} \$ 1,369$ trilhão. O valor de mercado do BB é também metade do valor do Bradesco, de R \$ 236 bilhões, que tem menos ativos, R \$ 1,211 trilhão.

O Banco do Brasil tem como desvantagens possuir maior parte do seu controle nas mãos do governo federal, e consequentemente menos liberdade na definição de suas políticas de atuação, de acordo com Pavini (2018), a explicação para a diferença dos valores de mercado dos demais bancos para o Banco do Brasil reside encontra-se no retorno oferecido pelos dois bancos privados, Itaú e Bradesco, superior ao do BB, e o risco de interferência do governo no banco federal.

O Banco do Brasil, apesar das desvantagens citadas ainda se encontra em uma posição diferente da Caixa Econômica Federal, que é uma empresa 100\% pública, que não tem capital aberto, isto é, ações negociadas em bolsa de valores ao contrário do Banco do Brasil, por exemplo, empresas de economia mista, com capital público e privado.

Por se enquadrar no Novo Mercado, o banco se fortifica no perfil de governança corporativa. Aliado a este fato, os preços descontados para as cotações da BBAS3 em relação aos seus pares e a média histórica do mercado, o identifica como uma boa oportunidade de investimento de longo prazo em relação aos preços das ações do banco, mesmo considerando as dificuldades pela qual o setor bancário vem enfrentando.

Em relação aos pares das ações do Banco do Brasil, as ações do Itaú, segundo dados do Banco Central do Brasil, é a maior companhia do setor bancário e a que apresenta maior rentabilidade patrimonial, nos últimos doze meses, sendo considerado o ativo mais atrativo para distribuição de lucros. O Bradesco apresenta 
uma rentabilidade patrimonial um pouco abaixo do Itaú, além de possuir um dividend yield relativamente baixo. As ações do Bradesco não apresentam atrativos para investimentos devido ao fator diversificação, quando comparadas com as ações do Itaú e do Banco do Brasil. Por fim, as ações do Banco do Brasil, que conjuntamente com os modelos CAPM são o objeto de estudo do presente trabalho, é uma ação que possui preferência em virtude de oferecer bons ganhos de capital em relação as demais do setor bancário. A Figura 3 apresenta um resumo que ajuda a justificar a escolha das ações do Banco do Brasil como objeto de estudo.

Figura 3: Quadro comparativo

\begin{tabular}{|c|c|c|c|c|c|c|c|}
\hline Empresa & $\begin{array}{l}\text { Dividend } \\
\text { Yield }\end{array}$ & $\begin{array}{l}\text { Retorno } 12 \\
\text { meses }\end{array}$ & $P / L$ & $\begin{array}{l}\text { P / } \\
\text { VPA }\end{array}$ & $\begin{array}{l}\text { Valor de } \\
\text { Mercado (R\$ } \\
\text { mil) }\end{array}$ & ROE & $\begin{array}{l}\text { Margem } \\
\text { Líquida }\end{array}$ \\
\hline BANRISUL & $8,46 \%$ & $66,56 \%$ & 6,87 & 1,24 & $9.021 .218,09$ & $18,11 \%$ & $13,79 \%$ \\
\hline BRADESCO & $2,83 \%$ & $29,60 \%$ & 14,32 & 2,20 & $254.855 .379,36$ & $15,47 \%$ & $16,83 \%$ \\
\hline $\begin{array}{l}\text { BANCO DO } \\
\text { BRASIL }\end{array}$ & $3,10 \%$ & $51,19 \%$ & 11,27 & 1,47 & $135.933 .899,33$ & $13,81 \%$ & $9,20 \%$ \\
\hline $\begin{array}{l}\text { BTG } \\
\text { PACTUAL }\end{array}$ & $2,51 \%$ & $47,93 \%$ & 28,48 & 1,27 & $24.248 .218,93$ & $4,45 \%$ & $11,37 \%$ \\
\hline $\begin{array}{l}\text { ITAÚ } \\
\text { UNIBANCO }\end{array}$ & $5,79 \%$ & $30,94 \%$ & 13,90 & 2,56 & $333.091 .545,76$ & $16,65 \%$ & $17,29 \%$ \\
\hline
\end{tabular}

Fonte: Banco Central do Brasil (2018).

Desta forma, neste trabalho será analisada a série histórica das cotações das ações BBAS3, para o período de janeiro de 1998 a dezembro de 2018, sob a ótica do modelo CAPM e seus modelos alternativos C-CAPM e I-CAPM, com a finalidade de identificar o modelo de precificação de ativos que fornece a melhor avaliação para as ações do BB. Esta opção foi feita, pois representam modelos que podem ser testados empiricamente por meio de ativos individuais.

Araújo, Bressan e Bertuccil (2004) propõe-se modelar o quadrado dos resíduos por meio do ARCH-M generalizado e será utilizado neste trabalho dada maior robustez e maior aplicabilidade aos problemas de finanças. 
De acordo com o Barbosa (2010), o CAPM foi desenvolvido teoricamente para um mercado perfeito, e foi adotado por quase todo o mundo, apesar das evidentes diferenças entre os mercados mundiais. Foram levantados questionamentos enquanto a sua aplicabilidade em modelo único em várias realidades.

\subsection{Descrição dos modelos econométricos aplicados}

O Banco do Brasil apesar de toda influência a que se sujeitam as companhias estatais e das circunstâncias adversas, com juros mais baixos, tem conseguido se preservar suas ações como um ativo atrativo para o longo prazo e o seu setor de atuação tem se destacado dentre os outros. Dessa forma, as medidas adotadas pela empresa e seus bons fundamentos podem sugerir uma perspectiva de alta para o ativo no longo prazo. Assim, destacamos que a magnitude das políticas monetária e fiscal, a elevação nos juros dos EUA ou a ameaça ao desequilíbrio dos fundamentos que compõem o tripé econômico, baseado em metas de inflação, câmbio flutuante e responsabilidade fiscal, são fatores que podem promover a reavaliação desta análise.

Com base na afirmação assim, justifica-se a escolha pelos modelos CAPM Intertemporal e CAPM Condicional.

\subsubsection{CAPM}

Definindo $r_{t}(N x 1)$ como vetor que representa o excesso de retornos dos $\mathrm{N}$ ativos do mercado, o modelo pode ser representado:

$$
\begin{aligned}
& r_{t}=\alpha+\beta r_{m t}+\varepsilon_{t} \\
& E\left[\varepsilon_{t}\right]=0 \\
& E\left[\varepsilon_{t} \varepsilon_{t}^{\prime}\right]=\sum \\
& E\left[\left(r_{m t}\right)\right]=\mu_{m} \\
& E\left[\left(r_{m t}-\mu_{m}\right)^{2}\right]=\sigma_{m}^{2} \\
& \operatorname{Cov}\left[r_{m t}, \varepsilon_{t}\right]=0
\end{aligned}
$$


$\beta$ é um vetor $(N x 1)$ para os betas, $r_{m t}$ é um vetor $(N x 1)$ para o excesso de retorno do mercado, $\alpha$ o vetor para os interceptos $(N x 1)$ e $\varepsilon_{t}$ é o vetor dos erros $(N x 1)$. $\sum$ é a matriz $(N x N)$ de variância-covariância. A função densidade de probabilidade é definida segundo Campbell, Lo e Mackinlay (1997) pela equação:

$$
f\left(r_{t} / r_{m t}\right)=(2 \pi)^{-\frac{N}{2}}|\Sigma|^{-\frac{1}{2}} x \exp \left[-\frac{1}{2}\left(r_{t}-\alpha-\beta r_{m t}\right)^{\prime} \Sigma^{-1}\left(r_{t}-\alpha-\beta r_{m t}\right)\right]
$$

Assumindo que os retornos são temporariamente IID, a FDP conjunta pode ser definida como:

$$
\begin{aligned}
& f\left(r_{1}, r_{2}, \ldots, r_{T} / r_{m 1}, r_{m 1}, \ldots, r_{m T}\right)=\prod_{t=1}^{T} p\left(r_{t} / r_{m t}\right. \\
& =\prod_{t=1}^{T}(2 \pi)^{-\frac{N}{2}}|\Sigma|^{-\frac{1}{2}} x \exp \left[-\frac{1}{2}\left(r_{t}-\alpha-\beta r_{m t}\right)^{\prime} \Sigma^{-1}\left(r_{t}-\alpha-\beta r_{m t}\right)\right]
\end{aligned}
$$

A função de máxima verossimilhança será dada por:

$$
L(\alpha, \beta, \Sigma)=-\frac{N T}{2} \log (2 \pi)-\frac{T}{2} \log |\Sigma|-\frac{1}{2} \sum_{t=1}^{T}\left(r_{t}-\alpha-\beta r_{m t}\right)^{\prime} \Sigma^{-1}\left(r_{t}-\alpha-\beta r_{m t}\right)
$$

Maximizando os parâmetros em relação a L chega-se a:

$$
\begin{aligned}
& \frac{\partial L}{\partial \alpha}=\Sigma^{-1}\left[\sum_{t=1}^{T}\left(r_{t}-\alpha-\beta r_{m t}\right)\right] \\
& \frac{\partial L}{\partial \beta}=\Sigma^{-1}\left[\sum_{t=1}^{T}\left(r_{t}-\alpha-\beta r_{m t}\right) r_{m t}\right] \\
& \frac{\partial L}{\partial \Sigma}=-\frac{T}{2} \Sigma^{-1}+\frac{1}{2} \Sigma^{-1}\left[\sum_{t=1}^{T}\left(r_{t}-\alpha-\beta r_{m t}\right)^{\prime}\left(r-\alpha-\beta r_{m t}\right)\right] \Sigma^{-1}
\end{aligned}
$$


Igualando a 0 resolvendo o sistema tem-se:

$$
\begin{aligned}
& \hat{\alpha}=\hat{\mu}-\hat{\beta} \hat{\mu}_{m} \\
& \hat{\beta}=\frac{\sum_{t=1}^{T}\left(r_{t}-\hat{\mu}\right)\left(r_{m t}-\hat{\mu}_{m}\right)}{\sum^{T}\left(Z_{m t}-\hat{\mu}_{m}\right)^{2}} \\
& \hat{\Sigma}=\frac{1}{T}\left[\sum_{t=1}^{T}\left(r_{t}-\hat{\alpha}-\hat{\beta} r_{m t}\right)\left(r_{t}-\hat{\alpha}-\hat{\beta} r_{m t}\right)^{\prime}\right]
\end{aligned}
$$

Onde:

$$
\begin{aligned}
& \hat{\mu}=\frac{1}{T} \sum_{t=1}^{T} r_{t} \\
& \hat{\mu_{m}}=\frac{1}{T} \sum_{t=1}^{T} r_{m t}
\end{aligned}
$$

\subsubsection{CAPM Condicional}

Pelo fato de que o principal propósito deste estudo é aplicar o CAPM condicional ao mercado acionário brasileiro, não seria possível fazê-lo sem a aplicação de um modelo econométrico que capte a variância condicional evoluindo com o tempo.

Jagannathan e Wang (1996) aplicam o GMM - "Generalized Method of Moments" ou métodos dos momentos generalizados. Ao testarem o CAPM condicional com a inserção de um fator humano. Da mesma forma Tambosi (2003) utiliza o mesmo modelo, e aplica nos mercados americano, chileno, argentino e brasileiro, adicionado também o fator humano. O resultado demonstrado pelos autores citados anteriormente e obtido através do CAPM condicional estimado pelo método de momentos generalizados é mais robusto do que a aplicação do CAPM estático.

Engle (1982) introduziu um procedimento para possibilitar a análise da variância condicional, este modelo é conhecido como ARCH - “AutoRegressive 
Conditional Heterocedastic". A princípio foi utilizado para estimar a variância da inflação.

Ponto importante e que deve ser destacado a estimação dos modelos da família ARCH contempla o método da verossimilhança, que permite a estimação simultânea da equação no nível da série $y_{t}$ e da equação de sua variância condicional $h_{t}$.

Ao assumir que $\varepsilon_{t}$ tem distribuição Normal condicional, o logaritmo da função de verossimilhança a ser maximizada é:

$$
\ln L(y / x ; 0)=-\frac{T}{2} \ln (2 \pi)-\frac{1}{2} \sum_{t=1}^{T} \ln h_{t}-\frac{1}{2} \sum_{t=1}^{T} \frac{\left(y_{t}-x_{1} \beta\right)^{2}}{h_{t}}
$$

Segundo Fava (2000) tal generalização assemelha-se ao modelo ARMA. Neste ponto, a variância condicional não depende somente dos quadrados dos choques aleatórios que aconteceram nos $m$ instantes de tempo instantaneamente anteriores, mas, sobretudo, das próprias variâncias condicionais dos $s$ instantes de tempos subitamente anteriores.

Segundo Morettin (2008) quando se diz que os preços (retornos) não são previsíveis pretende-se dizer sobre a não possibilidade de previsão de retornos "anormais". Ou seja, modelos considerados verdadeiros pelo mercado em geral não são eficientes para a estimação de retornos.

Como o próprio nome já indica, o modelo para heterocedasticidade condicional auto regressiva tem por objetivo modelar e gerar previsões para a variância condicional de uma série de tempo.

Tal modelagem é aplicável tanto no caso em que o nível da séria $y_{t}$ é descrito por um modelo ARIMA $(p, d, q)-\varphi(B) \mathrm{V}^{d} y_{c}=\theta(B) \varepsilon_{t}$ - quanto à situação em que $y$ té explicado por um modelo de Regressão Linear $-y_{t}=x_{t} \beta+\varepsilon_{t}$.

Nas duas formas, $\varepsilon t$ é, por hipótese, um ruído branco, representado por: 


$$
\begin{gathered}
E\left(\varepsilon_{t}\right)=0 \\
\mathrm{E}\left(\varepsilon_{t} \varepsilon_{s}\right)=\left\{\begin{array}{l}
0 \text { para } \mathrm{t} \neq \mathrm{s} \\
\sigma_{\varepsilon}^{2} \text { para } \mathrm{t}=\mathrm{s}
\end{array}\right.
\end{gathered}
$$

Desta forma, a variância não condicional de $\varepsilon t$ continua não variando no tempo. Já a variância $\varepsilon t$, condicional às informações disponíveis até os instantes $t$ -1 - It-1 - pode variar no tempo. Denominado $h_{t}$ a variância condicional de $\varepsilon_{t}$ temse:

$$
h_{t}=V\left(\varepsilon_{t} / I_{t-1}\right)=E\left(\varepsilon_{t}^{2} / I_{t-1}\right)=E_{t-1}\left(\varepsilon_{t}^{2}\right) \neq \text { constante }
$$

Para ilustrar a variância condicional, se $\varepsilon t$ for expresso pela equação $h t=$ $\alpha_{0}+\alpha_{1} \varepsilon_{t-1}$

Com base neste modelo, a variância condicional de $\varepsilon t$ depende do choque aleatório ocorrido no instante t-1. Assim o modelo ARCH acondiciona frações de períodos de alta e baixa volatilidade.

A fim de garantir que a variância condicional seja positiva é mandatório a imposição de algumas restrições, essas sendo: $\alpha 0>0$ e $\alpha 1 \geq 0$.

Já a variância não condicional de $\varepsilon t$ é, nesse caso, dada por $\sigma_{\varepsilon}^{2}=\frac{\alpha_{0}}{1-\alpha_{1}}$.

Adicionalmente deve-se impor a restrição $\alpha_{1}<1$. Neste formato a relação entre variância condicional e a não condicional de $\varepsilon t$ é dada pela seguinte equação:

$$
h_{t}-\sigma_{\varepsilon}^{2}=\alpha_{1}=\left(\varepsilon_{t-1}^{2}-\sigma_{\varepsilon}^{2}\right)
$$

Com base na expressão 12, sempre que o quadrado do choque aleatório no instante $t-1\left(\varepsilon_{t-1}^{2}\right)$ for maior do que sua esperança não condicional $\left(\sigma_{\varepsilon}^{2}\right)$ variância condicional de $\varepsilon t$ superará sua variância não condicional Pode-se destacar que sempre quando ocorrer eventos surpreendentes a volatilidade da série $y_{t}$ aumentará. 
De forma geral, a variância condicional $h$ tpode ser expressa como função dos choques aleatórios ocorridos nos $m$ instantes imediatamente anteriores. Temse, então, o modelo $\operatorname{ARCH}(m)$ :

$$
h_{t}=\alpha_{0}+\alpha_{1} \varepsilon_{t-1}^{2}+\alpha_{2} \varepsilon_{t-2}^{2}+\ldots+\alpha_{m} \varepsilon_{t-m}^{2}
$$

A variância não condicional de $\varepsilon_{t}$ é agora dada por:

$$
\sigma_{\varepsilon}^{2}=\frac{\alpha_{0}}{1-\sum_{t-1}^{m} \alpha_{1}}
$$

Assim, para que ambas as variâncias sejam positivas e finitas faz-se necessário que $\alpha_{0}$ f $0, \alpha_{1}, \alpha_{2}, \ldots, \alpha_{m} \geq 0$ e $\sum_{i=1}^{m} \alpha_{i}$ p 1 .

\subsection{Variáveis utilizadas}

Para formar as variáveis que compõem o CAPM, o CAPM condicional e o CAPM intertemporal foram obtidos as cotações mensais das ações do BBAS3 do $\mathrm{BB}$, por meio da plataforma de dados Economática, além do índice Ibovespa, da taxa Selic que representarão respectivamente o retorno da carteira de mercado e ativo livre de risco.

Segundo Brooks (2008), quando o objeto de análise é uma série de preços, por diversas razões estatísticas relacionadas à estacionariedade, tais séries devem ser convertidas em séries de retornos. Existem dois métodos para o cálculo do retorno das séries de preços, o que pressupõe a escolha entre a forma de capitalização discreta ou capitalização contínua, conforme as equações, respectivamente: 


$$
\begin{aligned}
R_{i, t} & =\frac{P_{i, t}-P_{i, t-1}}{P_{i, t-1}} \\
R_{i, t} & =\ln \left(\frac{P_{i, t}}{P_{i, t-1}}\right)=\ln P_{i, t}-\ln P_{i, t-1}
\end{aligned}
$$

Onde:

$R_{i, t}=$ o retorno da ação $i$ no período $t$;

$P_{i, t}=$ o preço da ação $i$, no período $t$, e

$P_{i, t-1}=$ preço da ação $i$, no período $t-1$.

Nielsen e Vassalou (2006) demonstram formalmente que as variáveis: taxa real de juros e o máximo índice de Sharpe, além da riqueza, precificam o I-CAPM. Eles concluem que os investidores somente fazem hedge contra mudanças nas médias, variâncias e covariâncias de retornos dos ativos que afetam a posição ou a inclinação da fronteira eficiente geral de investimento. Desta forma, neste trabalho, as variáveis de estado serão o índice máximo de Sharpe e a taxa real de juros.

De acordo com Oksendal (2007), os processos independentes podem ser identificados como equações de Ornstein-Uhlenbeck ou equações de Langevin, e para construir um modelo de valoração estimável, se identifica as variáveis $r$ e $\eta$, cuja solução é chamada de processo de Ornstein-Uhlenbeck. Desta maneira, a dinâmica do conjunto de oportunidade de investimento é completamente capturada por:

$$
\begin{aligned}
& d r=k_{r}(\bar{r}-r) d t+\sigma_{r} d z_{r} \\
& d \eta=k_{\eta}(\bar{\eta}-\eta) d t+\sigma_{t}+d z_{\eta}
\end{aligned}
$$

Segundo Almeida (2010), o modelo acima não é um modelo estrutural, micro-fundamentado, pois sua especificação não parte dos gostos, crenças e oportunidades dos investidores. No entanto, ele dá uma base simples para a característica essencial do I-CAPM, o apreçamento do risco associado com variações no conjunto de oportunidades de investimento instantânea considerando apenas duas variáveis de estado, $\mathrm{r}$ e $\eta$. O modelo assume que $\mathrm{r}$ e $\eta$ seguem um 
processo de Markov conjunto. Tal modelo implica que a taxa real de juros $r$ é estocástica e que todos os prêmios de risco são proporcionais ao índice de Sharpe estocástico $\eta$.

Para se estimar os parâmetros do modelo de reversão à média, estima-se a seguinte regressão, conforme Dixit \& Pindyck (1994):

$$
x_{t}-x_{t-1}=a+b x_{t-1}+\varepsilon_{t}
$$

E calculam-se os parâmetros:

$$
\bar{x}=-a / b
$$

$$
\phi=-\ln (1+b)
$$

$$
\sigma=\sigma_{\varepsilon} \sqrt{\frac{2 \ln (1+b)}{(1+b)^{2}-1}}
$$

Onde $\sigma_{\varepsilon}$ é o desvio-padrão da regressão.

O excesso de retorno, ou prêmio de risco, de um ativo i é uma função linear do excesso de retorno do retorno de mercado e das inovações das variáveis de estado r e $\eta$, desta forma, tem-se:

$$
R_{i}-R_{f}=a_{i}+\beta_{i M}\left(R_{M}-R_{f}\right)+\beta_{i \eta} \Delta r+\varepsilon_{i}
$$

Onde as inovações nas variáveis de estado: $\mathrm{r}$ e $\eta$ são estimadas usando os parâmetros estimados da equação (22). 


\subsection{Testes de robustez realizados}

Apesar de todas as variáveis já se apresentarem em primeira diferença, foram realizados os testes de raiz unitária para verificar se as séries são realmente estacionárias e não incorrer o risco de obtenção de regressões espúrias. 


\section{ANÁLISE DOS RESULTADOS}

Este capítulo apresentará os resultados obtidos com a análise da série histórica dos valores de cotação e da variação dos retornos das ações do Banco do Brasil - BBAS3, que se encontra no Anexo 1 do presente trabalho. A seção 4.1 apresenta os testes de raiz unitária e as estatísticas descritivas; a seção 4.2 apresenta o teste realizado para o modelo CAPM com beta estático; a seção 4.3 apresenta o CAPM com betas dinâmicos; por fim, a seção 4.4 aborda a estimativa dos parâmetros de aversão relativa ao risco.

\subsection{Estatísticas descritivas e testes de raiz unitária}

De acordo com Fellet (2016), o teste de raízes unitárias deve ser realizado para que seja possível verificar se a série é estacionária ou não. A estacionariedade é uma propriedade relevante e desejável, que se refere ao comportamento de uma variável em torno da sua média. Uma série que contém raiz unitária é não estacionária e, portanto, não pode ser utilizada para estimar uma regressão, pois a regressão seria espúria. Uma variável cuja série é estacionária permite que ela seja utilizada para generalização de seu comportamento para outros períodos de tempo, portanto, possível que seja utilizada em regressões e modelos de previsão.

Segundo Brooks (2008), a não rejeição da hipótese nula dos testes de raízes unitárias significa que a série da variável é não-estacionária, ou seja, significa que a série possui comportamento crescente ou decrescente, terá uma média, variância ou ambas variando ao longo do tempo. Isso geralmente ocorre quando são utilizadas séries de preços. Entretanto, nesse estudo são utilizadas apenas séries de retornos, ou seja, as variáveis já em primeira diferença. É esperado que séries de retornos apresentassem estacionariedade.

Com o objetivo de verificar se a série possui mais de uma raiz unitária foi utilizado o software R, sendo realizado o teste de Dickey Fuller Aumentado (ADF). $\mathrm{O}$ ADF testa processos individuais de raiz unitária de modo que pode variar na série. Este teste é caracterizado pela combinação de testes de raiz unitária individual para derivar um resultado comum. 
A Tabela 2 apresenta as estatísticas descritivas para os excessos de retornos do ativo pesquisado

Tabela 2: Estatísticas descritivas dos excessos de retorno do ativo BBAS3, período de Jan/1998 - Dez/2018.

\begin{tabular}{|l|r|}
\hline Média & $2,22 \%$ \\
\hline Erro padrão & $0,78 \%$ \\
\hline Mediana & $1,02 \%$ \\
\hline Modo & $-13,16 \%$ \\
\hline Desvio padrão & $12,05 \%$ \\
\hline Variância da amostra & $1,45 \%$ \\
\hline Curtose & 1,29 \\
\hline Assimetria & 0,31 \\
\hline Intervalo & $82,64 \%$ \\
\hline Mínimo & $-35,09 \%$ \\
\hline Máximo & $47,55 \%$ \\
\hline Soma & $534,94 \%$ \\
\hline Contagem & 241,00 \\
\hline
\end{tabular}

Fonte: Elaboração própria.

Observa-se no ativo analisado que não houve excesso de retorno positivo. A análise da tabela permite identificar alguns "fatos estilizados" presentes em séries financeiras descritas por Daníelsson (2011). O valor de curtose menor que 3 encontrado no ativo é sinal que a distribuição não tem caudas pesadas e que segue uma distribuição normal.

A próxima etapa será testar se a série REM raiz unitária. Os testes utilizados serão o de Augmented Dickey-Fuller (ADF) e o Kwiatkowski-Phillips-Schmidt-Shin (KPSS). A hipótese nula do teste KPSS é que a série é estacionária. Todos os excessos de retornos foram testados simulando a presença de tendência determinística e constante, e com a presença apenas da constante. A Tabela 3 apresenta o resultado dos testes. 
Tabela 3: Estatística calculada pelos testes de raiz unitária ADF e KPSS.

\begin{tabular}{ccccc}
\hline & ADF & \multicolumn{2}{c}{ KPSS } \\
\hline Ativo & $\begin{array}{c}\text { Tendência e } \\
\text { intercepto }\end{array}$ & Intercepto & $\begin{array}{c}\text { Tendência } \\
\text { e } \\
\text { intercepto }\end{array}$ & Intercepto \\
\hline BBAS3 & -66.92279 & -66.89430 & 0.112887 & 0.393895 \\
\hline
\end{tabular}

Fonte: Elaboração própria. Os valores do teste ADF indicam rejeição da hipótese nula a $5 \%$.

Os valores do teste KPSS indicam não rejeição da hipótese nula a 5\%.

\subsection{Teste com o modelo de CAPM para beta estático}

A Tabela 4 apresenta os parâmetros estimados do modelo CAPM com o beta estático. As variâncias foram controladas por meio dos modelos GARCH estimados com os erros seguindo uma distribuição t-student. A estimação dos erros com a distribuição $t$-student controla o fato estilizado de caudas pesadas. Pelo critério de Scharz a distribuição $t$ também apresentou um melhor desempenho do $\alpha$ distribuição normal dos erros. Para retirar-se a influencia da correlação serial nos excessos de retornos foram estimadas estruturas auto regressivas e utilizando o resíduo da serie sem correlação serial.

$$
\begin{aligned}
& r_{i t}=\alpha_{i}+\beta_{i} r_{m t}+\varepsilon_{i t} \\
& \sigma_{i t}^{2}=\omega_{i}+\sum_{h=1}^{p} b_{i h} \sigma_{i, t-h}^{2}+\sum_{h=1}^{q} a_{i h} \varepsilon_{i, t-h}^{2}
\end{aligned}
$$

Tabela 4: Modelo CAPM com o beta estático.

\begin{tabular}{ccccccccc}
\hline Ativo & $\boldsymbol{\alpha} \mathbf{X ~ \mathbf { 1 0 } ^ { \mathbf { 4 } }}$ & $\boldsymbol{\beta}$ & $\boldsymbol{\omega} \mathbf{X ~ 1 0} \mathbf{1 0}^{\mathbf{4}}$ & $\mathbf{a}_{1}$ & $\mathbf{a}_{2}$ & $\mathbf{a}_{3}$ & $\mathbf{b}_{1}$ & $\mathbf{b}_{2}$ \\
\hline BBAS3 & $-1,84$ & 0,82 & 0,02 & 0,23 & 0,21 & & 0,97 & \\
\hline
\end{tabular}

Fonte: Elaboração própria. O valor de $\alpha X 10^{4}$ indica não significância a $10 \%$.

Percebe-se que a hipótese do modelo de que o intercepto da equação da média condicional deve ser insignificante foi satisfeito. $O$ beta estimado foi significativo a $1 \%$, como também os parâmetros do modelo $\mathrm{GARCH}$ foram 
significantes a $5 \%$. O beta estimado caracteriza que a ação BBAS3 é considerada defensiva para os investidores. Esse resultado já era esperado dado que as ações que permanecem por longo tempo no Ibovespa, como é o caso da BBAS3 são consideradas mais seguras pelos agentes. As estruturas GARCH foram escolhidas de acordo com o critério de Schwarz, pois o mesmo penaliza pelo número de parâmetros e escolhe o mais parcimonioso. A maior estrutura $\mathrm{ARCH}$ encontrado foi de ordem 3 e a maior estrutura GARCH foi de ordem 2. A maior parte dos excessos de retornos ajustou-se bem a um GARCH $(1,2)$. A Tabela 5 (nunca se menciona seguinte, abaixo e e etc) apresenta o teste $\mathrm{Q}$ feito nos resíduos padronizados e nos resíduos padronizados o quadrado das séries, a fim de verificar se os resíduos não apresentam correlação serial.

Tabela 5: Diagnóstico dos resíduos.

\begin{tabular}{ccccccccc}
\hline Ativo & $\mathbf{Q}_{\mathbf{1}}(\mathbf{5})$ & $\mathbf{Q}_{\mathbf{1}}(\mathbf{1 0})$ & $\mathbf{Q}_{\mathbf{1}}(\mathbf{1 5})$ & $\mathbf{Q}_{\mathbf{1}}(\mathbf{2 0})$ & $\mathbf{Q}_{\mathbf{2}}(\mathbf{5})$ & $\mathbf{Q}_{\mathbf{2}}(\mathbf{1 0})$ & $\mathbf{Q}_{\mathbf{2}}(\mathbf{1 5})$ & $\mathbf{Q}_{\mathbf{2}}(\mathbf{2 0})$ \\
\hline BBAS3 & 4.35 & 9.3 & 12.80 & 16.4 & 4.41 & 5.00 & 13.77 & 19.56 \\
\hline
\end{tabular}

Fonte: Elaboração própria.

De acordo com exposto acima, pode se dizer que o modelo estimado conseguiu retirar a estrutura presente nos excessos de retorno.

Na próxima etapa deve-se verificar se o beta estimado pelo modelo explica o excesso de retorno médio por meio da equação desenvolvida por Fama e Macabeth (1973).

$$
R_{a}=\kappa_{0}+\kappa_{1} \beta_{a}+\kappa_{2} \beta_{a}^{2}+\kappa_{3} S_{e a}+\eta_{a}
$$

Tabela 6: Estimativa da equação do beta estático.

\begin{tabular}{|c|c|c|c|c|c|c|c|}
\hline Modelo & $\mathbf{K}_{\mathbf{0}}$ & $\mathbf{K}_{1}$ & $\mathbf{K}_{2}$ & $\mathbf{K}_{\mathbf{3}}$ & Teste LM & $\begin{array}{l}\text { Teste } \\
\text { White }\end{array}$ & $\begin{array}{l}\text { Teste JB } \\
\text { (p-valor) }\end{array}$ \\
\hline 1 & $\begin{array}{c}- \\
0,058 * * * \\
-\end{array}$ & $0,058 * * *$ & $\begin{array}{c}- \\
0,063 * * *\end{array}$ & $\begin{array}{c}- \\
0,031 * * *\end{array}$ & 0,59 & 0,49 & 0,78 \\
\hline 2 & $0,023 * * *$ & $0,062 * * *$ & $-0,01058$ & & 0,05 & 0,44 & 0,32 \\
\hline
\end{tabular}




\begin{tabular}{|c|c|c|c|c|c|}
\hline & - & - & & & \\
\hline 3 & $0,004 * * *$ & $0,008 * * *$ & 0,05 & 0,65 & 0,33 \\
\hline 4 & & $0,002 * * *$ & 0,06 & 0,32 & 0,3 \\
\hline
\end{tabular}

Fonte: Elaboração própria. *** indica não significância a $10 \%$.

Desta forma, percebe-se que para o caso brasileiro os betas estáticos não têm poder de explicação sobre os excessos de retornos médios, o que está em linha com a proposição de Jagannathan e Wang (1996). A única variável com poder de explicação dos excessos de retornos cross-section foi a variância dos resíduos e como uma relação inversa indicando que um aumento na variância residual diminui o excesso de retorno médio do ativo. Com os betas estáticos não tem um poder de explicação e consequentemente não são uma boa medida de risco não diversificável, o passo seguinte da pesquisa será estimar os betas dinâmicos para a ação analisada, sendo esta a BBAS3.

\subsection{Teste com o modelo de CAPM para beta dinâmico}

A primeira etapa para testar o CAPM com os betas dinâmicos é a estimação dos mesmos. Eles serão estimados por meio do modelo MGARCH DCC desenvolvido por Tse e Tsui (2002). Para a equação da média foi estimado vetor auto regressivo para retirar a correlação serial e utilizar os resíduos dessa estimação. Desta maneira, o modelo fornecerá a covariância condicional e a variância condicional. Para recuperar o beta condicional dividi-se a covariância condicional entre o ativo pela variância condicional do excesso de retorno do mercado. No mercado financeiro sabe-se que o mercado sobe com a baixa volatilidade e cai com a alta volatilidade. Caso a série apresente essa assimetria será utilizado o modelo TGARCH desenvolvido por Glosten, Jaganathan e Runkle (1993). Esse modelo coloca uma dummy que representa quando a inovação do retorno na equação da variância é negativa. Dessa forma dar-se um peso maior os retornos negativos. Para o ativo em análise foi estimado o modelo com e sem assimetria e escolhido o melhor modelo de acordo com o critério de informação de Schwarz. A Tabela 7 apresenta o resultado. 
Tabela 7: Modelo MGARCH DCC

\begin{tabular}{lcccccccccc}
\hline \multicolumn{1}{c}{ Ativo } & $\omega \times 10^{4}$ & $\mathrm{a}_{1}$ & $\mathrm{a}_{2}$ & $\mathrm{~b}_{1}$ & $\mathrm{~b}_{2}$ & $\gamma_{1}$ & $\gamma_{2}$ & $\theta_{1}$ & $\theta_{2}$ & $\rho_{\mathrm{i}, \text { ibov }}$ \\
\hline BBAS3 & 0,02 & 0,16 & $-0,15$ & 1,41 & $-0,43$ & & & 0,97 & 0,01 & 0,76 \\
IBOV & 0,17 & 0,09 & 0,07 & 0,42 & 0,36 & & & & & \\
\hline
\end{tabular}

Fonte: Elaboração própria.

Destaca-se que os parâmetros estimados foram significantes a 5\% e todas as correlações não condicionais foram significantes a $1 \%$. A estimação multivariada obteve um melhor desempenho com os erros seguindo a distribuição $t$-student para o par de ativos analisados. A BBAS3 apresentou uma correlação não condicional grande com o IBOVESPA. Para controlar os resíduos não foi necessário mais do que duas defasagens do MGARCH. O próximo passo foi realizar a estimativa do beta por meio de um modelo de nível local com variância do nível fixa e o beta variando no tempo. Os betas estimados pelos dois métodos serão testados se os mesmos têm poder de explicação sobre o retorno médio cross section.

Tabela 8: Diagnóstico dos resíduos MGARCH.

\begin{tabular}{lcccccccc}
\hline \multicolumn{1}{c}{ Ativo } & $\mathbf{Q}_{\mathbf{1}} \mathbf{( 5 )}$ & $\mathbf{Q}_{\mathbf{1}}(\mathbf{1 0})$ & $\mathbf{Q}_{\mathbf{1}}(\mathbf{1 5})$ & $\mathbf{Q}_{\mathbf{1}}(\mathbf{2 0})$ & $\mathbf{Q}_{\mathbf{2}}(\mathbf{5})$ & $\mathbf{Q}_{\mathbf{2}}(\mathbf{1 0})$ & $\mathbf{Q}_{\mathbf{2}}(\mathbf{1 5})$ & $\mathbf{Q}_{\mathbf{2}}(\mathbf{2 0})$ \\
\hline BBAS3 & 4,08 & 8,82 & 15,66 & 19,67 & 1,96 & 5,99 & 16,29 & 24,29 \\
IBOV & 12,36 & 20,35 & 26,18 & 32,27 & 6,61 & 22,94 & 25,76 & 30,94 \\
\hline
\end{tabular}

Fonte: Elaboração própria.

O beta estrutural consegue acompanhar o movimento do beta condicional. O beta condicional apresenta um comportamento mais "nervoso" em relação ao beta estrutural. Além do beta condicional e estrutural, foi estimado a variância condicional para o ativo pesquisado. A análise da variância condicional é importante no mercado financeiro, pois é a partir da mesma que é calculado o VaR (Value-at-Riski), outra medida de risco bastante utilizada.

A Tabela 9 apresente os betas médios estimados pelos dois modelos. Notase que na média os betas estimados pelos dois modelos têm valores próximos, 
indicando que apesar da trajetória dos mesmos serem muitas vezes distintas, no longo prazo eles são equivalentes.

Tabela 9: Betas dinâmicos médios.

\begin{tabular}{ccc}
\hline Ativo & $\begin{array}{c}\text { Beta condicional } \\
\text { médio }\end{array}$ & $\begin{array}{c}\text { Beta estrutural } \\
\text { médio }\end{array}$ \\
\hline BBAS3 & 0,82 & 0,43 \\
\hline \multicolumn{2}{c}{ Fonte: Elaboração própria. }
\end{tabular}

O próximo passo foi a verificação se o beta condicional e estrutural médio explicam os retornos cross section. O resultado pode ser verificado na Tabela 10.

Tabela 10: Estimativa da equação dos excessos de retornos cross section com betas condicionais.

$$
R_{a}=\kappa_{0}+\kappa_{1} \beta_{a}+\kappa_{2} \beta_{a}^{2}+\kappa_{3} S_{e a}+\eta_{a}
$$

\begin{tabular}{cccccccc}
\hline Modelo & $\mathbf{K}_{\mathbf{0}}$ & $\mathbf{K}_{\mathbf{1}}$ & $\mathbf{K}_{\mathbf{2}}$ & $\mathbf{K}_{\mathbf{3}}$ & $\mathbf{Q}_{\mathbf{1}(\mathbf{5})}$ & $\mathbf{Q}_{\mathbf{2}(\mathbf{5})}$ & $\begin{array}{r}\text { Teste JB } \\
\text { (p-valor) }\end{array}$ \\
\hline 1 & $-0,0066^{* *}$ & $0,0210^{*}$ & $-0,0135^{* *}$ & $-0,0003^{* * *}$ & 8,86 & 2,35 & 0,98 \\
2 & $-0,0059$ & 0,0163 & $-0,01058$ & & 1,43 & 2,67 & 0,15 \\
3 & $0,0014^{*}$ & $-0,0018^{*}$ & & & 8,43 & 5,84 & 0,43 \\
4 & & $0,0005^{* * *}$ & & & 11,96 & 1,31 & 0,30 \\
\hline
\end{tabular}

Fonte: Elaboração própria. *** e *** indicam não significância a 1\%, 5\% e $10 \%$.

De acordo com a Tabela 10, verifica-se uma melhora do poder de explicação do beta condicional médio em relação aos excessos de retornos médios cross section. Porém, quando testado sem o intercepto o beta não foi significativo, desta forma, chega-se a uma conclusão que o CAPM falha em muitas ocasiões e nem o ativo com maior risco não diversificável oferece o maior retorno esperado. $\mathrm{O}$ modelo ajusta-se bem a séries temporais da equação da média da estimação do beta estático, pois se verifica que o valor do intercepto é zero. Mesmo quando é rejeitada a hipótese nula de que o valor do intercepto é diferente de zero, esse valor e bem pequeno. Desta maneira, conclui-se que o mercado acionário brasileiro no período pesquisado não há indícios que a ação tem um maior risco não diversificável representado pelo beta ofereceu ao investidor um retorno maior. 
Tabela 11: Estimativa da equação dos excessos de retorno cross section com betas estruturais.

$$
R_{a}=\kappa_{0}+\kappa_{1} \beta_{a}+\kappa_{2} \beta_{a}^{2}+\kappa_{3} S_{e a}+\eta_{a}
$$

\begin{tabular}{|c|c|c|c|c|c|c|c|}
\hline Modelo & $\mathbf{K}_{\mathbf{0}}$ & $\mathbf{K}_{1}$ & $\mathbf{K}_{2}$ & $\mathbf{K}_{3}$ & $Q_{1(5)}$ & $\mathbf{Q}_{2(5)}$ & $\begin{array}{l}\text { Teste JB } \\
\text { (p-valor) }\end{array}$ \\
\hline 1 & $\begin{array}{c}- \\
0,0736^{* * *}\end{array}$ & $0,2951 * * *$ & $\begin{array}{c}- \\
0,2034 * * *\end{array}$ & $-0,0094 * * *$ & 8,93 & 1,56 & 0,21 \\
\hline 2 & $\stackrel{-}{-}, 0690^{* * *}$ & $0,2115^{* * *}$ & $\stackrel{-}{-} 0,1488^{* * *}$ & & 11,41 & 1,47 & 0,2 \\
\hline 3 & $0,0079 * * *$ & $-0,0086 * * *$ & & & 12,14 & 1,35 & 0,3 \\
\hline 4 & & $0,0012 * * *$ & & & 11,93 & 1,26 & 0,3 \\
\hline
\end{tabular}

Fonte: Elaboração própria. *,** e *** indicam não significância 1\%, 5\% e 10\%.

O beta estrutural não explica o retorno cross section, denotando que o teste CAPM segundo a metodologia de Fama e Mcbeth (1973) não se ajusta bem ao mercado acionário no Brasil.

Pode se inferir dos testes realizados que o beta constante serve apenas como referencia se a ação acompanha ou não o desempenho do mercado em um dado período, mas não ao ponto de servir como uma boa medida de risco. Isso se justifica, conforme foi demonstrado, que o beta não é constante. Já o beta dinâmico é uma melhor aproximação do risco de mercado, pois o mesmo aumento em períodos de crise e de aumento da aversão á risco.

O modelo de apreçamento de ativos é desenvolvido sob a hipótese de que os agentes do mercado têm aversão a risco, desta maneira, o próximo passo seria estimar os parâmetros que medem o quanto os agentes "exigem" do mercado para correr risco. 


\subsection{Apresentação do resultado dos modelos}

De acordo com Gujarati (2006), o teste F é utilizado na regressão em substituição do teste $\mathrm{t}$ para verificar a hipótese conjunta de que os verdadeiros coeficientes parciais angulares são simultaneamente iguais a zero. A hipótese nula do teste é que os coeficientes $(\beta 1, \beta 2, \beta 3$, etc.) conjuntamente são iguais a zero. Se a hipótese nula for verdadeira, significa que a relação entre a variável dependente e as independentes deve-se a efeitos aleatórios representados pelo termo de erro. Caso haja a rejeição da hipótese nula, as variáveis independentes exercem de fato influência sobre a dependente.

\subsubsection{CAPM}

Conforme pode ser observado na Tabela 12, o resultado do teste F apresenta um p-valor do teste F significante ao nível 1\% tanto para carteiras quanto para ativos individuais. Observa-se, ainda, que os interceptos não são significativamente diferentes de zero ao nível de confiança de 5\%, sugerindo ser um modelo consistente para explicar os retornos, visto que a suposta eficiência do mercado requer que os interceptos não sejam significativos.

Quanto ao coeficiente do prêmio de mercado, verifica-se que este é significativo ao nível de $5 \%$, pois o p-valor $(0,0000)$ para ativos individuais e carteiras são ambos significantes a $1 \%$. Estes resultados demonstram um alinhamento com a teoria do CAPM.

Tabela 12: Resumo dos resultados estatísticos do modelo CAPM.

\begin{tabular}{cccccccc}
\hline & Coeficiente & $\begin{array}{c}\text { Erro } \\
\text { padrão }\end{array}$ & $\begin{array}{c}\text { Estatística } \\
\mathbf{t}\end{array}$ & Prob. & $\mathbf{R}^{2}$ & $\begin{array}{c}\text { Prob. } \\
\text { Teste F }\end{array}$ \\
\hline \multirow{2}{*}{\begin{tabular}{c} 
Ativo individual \\
\cline { 2 - 6 } $\begin{array}{c}\text { Carteira } \\
\text { Ibovespa }\end{array}$
\end{tabular}} & $\alpha\left(\mathrm{R}_{\mathrm{mL}}-\mathrm{R}_{\mathrm{fL}}\right)$ & 0,643287 & 0,0576 & 11,167 & 0,0000 & 0,1272 & 0,0000 \\
\cline { 2 - 6 } & $\alpha$ & $-0,0045$ & 0,0031 & $-1,478$ & 0,1394 & \multirow{2}{*}{0,5611} & 0,0000 \\
\hline
\end{tabular}

Fonte: Elaboração própria. 


\subsubsection{CAPM condicional}

Nos resultados apresentados na Tabela 13 observa-se que os interceptos não são significativamente diferentes de zero em um nível de confiança de 5\%. Os resultados obtidos estão alinhados com os resultados de Mongrut (2006) e Sanvicente (2015) que não recomendam a inclusão do risco-país no modelo de precificação de ativos. Os coeficientes relativos ao prêmio de mercado com dados locais se apresentam significativos, pois o p-valor $(0,0000)$ para ativos individuais e carteiras, ambos significantes a $1 \%$.

Tabela 13: Resumo dos resultados estatísticos do modelo CAPM

Condicional

\begin{tabular}{|c|c|c|c|c|c|c|c|}
\hline & & Coeficiente & $\begin{array}{c}\text { Erro } \\
\text { padrão }\end{array}$ & $\begin{array}{c}\text { Estatística } \\
\mathbf{t}\end{array}$ & Prob. & $\mathbf{R}^{2}$ & $\begin{array}{c}\text { Prob. } \\
\text { Teste F }\end{array}$ \\
\hline \multirow{3}{*}{ Ativo individual } & $\alpha$ & 0,033407 & 0,010249 & 1,2481 & 0,2280 & \multirow{3}{*}{0,1289} & \multirow{3}{*}{0,0000} \\
\hline & $\beta\left(\mathrm{R}_{\mathrm{mL}}-\mathrm{R}_{\mathrm{fL}}\right)$ & 0,429024 & 0,046892 & 10,951 & 0,0000 & & \\
\hline & $\gamma \mathrm{R}_{\mathrm{c}}$ & $-15,811$ & 12,950 & $-1,2961$ & 0,1576 & & \\
\hline \multirow{3}{*}{$\begin{array}{l}\text { Carteira } \\
\text { Ibovespa }\end{array}$} & $\alpha$ & 0,046009 & 0,0206439 & 1,963 & 0,1593 & \multirow{3}{*}{0,5732} & \multirow{3}{*}{0,0000} \\
\hline & $\beta\left(\mathrm{R}_{\mathrm{mL}}-\mathrm{R}_{\mathrm{fL}}\right)$ & 0,74912 & 0,0642918 & 11,705 & 0,0000 & & \\
\hline & $\gamma \mathbf{R}_{\mathrm{c}}$ & $-17,237$ & 10,5291 & $-1,491$ & 0,1429 & & \\
\hline
\end{tabular}

Fonte: Elaboração própria.

\subsubsection{CAPM Intertemporal}

Observam-se na Tabela 14 os resultados obtidos pelo modelo CAPM Intertemporal que utilizando carteiras e também ativos individuais, foram obtidos interceptos significativamente diferentes de zero ao nível de confiança de $1 \%$, sugerindo inadequação do modelo na explicação dos retornos no mercado acionário brasileiro. Assim, sugere-se que outros fatores, não absorvidos pelo prêmio de mercado, podem estar influenciando a variação dos retornos. Estes resultados estão alinhados com Mongrut (2006) e Sanvicente (2015) que criticam a utilização de dados provenientes de mercados internacionais alegando que o mercado local pode estar suficientemente desenvolvido para incorporar informações relevantes sobre os riscos. 
Tabela 14: Resumo dos resultados estatísticos do modelo CAPM Intertemporal

\begin{tabular}{cccccccc}
\hline & Coeficiente & $\begin{array}{c}\text { Erro } \\
\text { padrão }\end{array}$ & $\begin{array}{c}\text { Estatística } \\
\mathbf{t}\end{array}$ & Prob. & $\mathbf{R}^{2}$ & $\begin{array}{c}\text { Prob. } \\
\text { Teste F }\end{array}$ \\
\hline \multirow{2}{*}{\begin{tabular}{c} 
Ativo individual \\
\cline { 2 - 6 } $\begin{array}{c}\text { Carteira } \\
\text { Ibovespa }\end{array}$
\end{tabular}} & $\alpha$ & $-0,015596$ & 0,0027 & $-3,288$ & 0,001 & \multirow{2}{*}{0,0706} & 0,0000 \\
\cline { 2 - 6 } & $\beta\left(\mathrm{R}_{\mathrm{mG}}-\mathrm{R}_{\mathrm{fG}}\right)$ & 0,460229 & 0,1239 & 4,521 & 0,0000 & & \\
\hline
\end{tabular}

Fonte: Elaboração própria. 


\section{CONSIDERAÇÕES FINAIS}

No presente trabalho foram descritos detalhes dos modelos de precificação de ativos citados na literatura selecionando parte do referencial teórico com foco no tema, mais especificamente sobre o CAPM, e modelos que vieram posteriormente ao sugerido por Sharpe (1964).

O objetivo principal do trabalho foi realizar a avaliação e comparar o modelo CAPM com seus modelos alternativos. Desta maneira foram estudados o modelo CAPM Condicional e o CAPM Intertemporal. Destaca-se que o modelo DCAPM foi apresentado, porém, neste trabalho, não foi utilizado para fins de comparação.

Com base nos testes realizados no capítulo quatro, pode se observar que o CAPM Intertemporal é o modelo menos adequado para explicação dos retornos, este fato se justifica a medida que, no ativo analisado o intercepto mostrou-se significativamente diferente de zero, contrariando a hipótese do mercado eficiente. Adicionalmente, foi o modelo que apresentou o menor poder explicativo, além de apresentar autocorrelação positiva, sugerindo especificação inadequada.

A inclusão do risco-país, que é amplamente sugerida pela literatura como adaptação dos modelos de precificação de ativos para os mercados emergentes, não se mostrou significativa na explicação dos retornos. Dessa forma a utilização modelo CAPM condicional não se mostrou viável no mercado acionário brasileiro.

Já ao analisar o CAPM, o beta referente ao prêmio de mercado apresenta-se significativo em todos os testes realizados. Então, deve-se avaliar se estimativas obtidas apenas com um único fator (prêmio de risco de mercado) podem ser mais consistentes e de menor custo, visto que o modelo CAPM é mais parcimonioso que os demais modelos.

Ao comparar o desempenho dos modelos, observou-se que alguns fatores possuem capacidade de ampliar o poder de explicação do retorno de ativos, e podese obter um apreçamento mais adequado ao mercado em análise. Entretanto a opção pela utilização de modelos mais complexos, apesar de seu desempenho superior, 
exige uma operacionalização mais criteriosa, incorrendo em maiores custos, sob pena da obtenção de estimativas imprecisas para o apreçamento de ativos.

Para futuras pesquisas fica a sugestão de serem estimados os betas pelos vários métodos oferecidos pelos modelos $\mathrm{MGARCH}$, como o $\mathrm{CCC}$, o $\mathrm{BEKK}$ e o próprio DCC de Engle e a verificação se os mesmos têm poder de explicação aos excessos de retorno cross section. Também podem ser pesquisados ativos de outros índices e não apenas do Ibovespa. De forma complementar, a realização dos testes apenas no mercado acionário brasileiro constitui uma limitação do trabalho. Como sugestão para futuras pesquisas, poderiam ser incluídos na amostra outros mercados emergentes, outros modelos de precificação de ativos e também testes da capacidade preditiva dos modelos. 


\section{REFERÊNCIAS BIBLIOGRÁFICAS}

ALMEIDA, L. A. Estimação do CAPM Intertemporal com ações da BOVESPA. Dissertação de Mestrado em Economia. Universidade de São Paulo. 2010

ALVES, J.S. Análise comparativa da validade dos modelos CAPM tradicional e condicional: o caso das ações da Petrobrás. Revista Ciênc. Admin., Fortaleza, v.13, n.1, p147-157, Agosto, 2007.

ARAUJO,E.A.T.; OLIVEIRA, V.C.; SILVA, .A. CAPM em estudos brasileiros: uma análise da pesquisa. RCO, v.6, n.15, p. 96-122. São Paulo, 2012.

ARAÚJO, D. L.; BRESSAN, A. B. E BERTUCCI, L. A. O risco de mercado do agronegócio brasileiro: uma análise comparativa entre os modelos CAPM e GARCHM. RGO Gestão Organizacional, Chapecó, v.2, n. 3, p. 207-220. 2004.

BACHELIER, Louis. Théorie de la spéculation. Gauthier-Villars, 1900.

BARBOSA, Claudio Alan de Melo. Análise comparativa dos modelos CAPM tradicional e condicional: um estudo de caso do clube de investimento. Dissertação de mestrado, p.88. Universidade Federal do Espírito Santo, 2009.

BENSON, Karen; FAFF, Robert. $\boldsymbol{\beta}$. In ABACUS, 2012.

BOLLESRLEV, Tim; ENGLE, Robert F.; WOOLDRIDGE, Jeffrey. A capital asset pricing model with time varying covariances. Journal of Political Economy n.96, p.116131. 1988.

BREALEY R. A., ALLEN F., MYERS C. S. Princípios de Finanças Empresariais. MC Graw Hill. 2008.

BRITO, N. R. O. Eficiência informacional fraca de mercados de capitais sob condições de inflação. Revista Brasileira de Mercado de Capitais, vol. 4, n. 10, p. 63-85, 1978.

BROOKS, C. Introductory Econometric for Finance. Cambridge University Press, 2008. 
Bali, Turan G., \& Engle, Robert F. The intertemporal capital asset pricing model with dynamic conditional correlations. Journal of Monetary Economics, n. 57, p. 377-390, 2010.

CAMARGOS, M. A. de; BARBOSA, F. VOL. Estudos de evento: teoria e operacionalização. 2003.

CARASSINI, Ronaldi. Estudo do CAPM condicional no mercado acionário brasileiro utilizando o modelo desenvolvido por Jagannathan e Wang (1996). Dissertação de mestrado em Administração, p.64. Escola de Gestão e Direito da Universidade Metodista de São Paulo, 2017.

CASTRO Silva, W. A. C.; PINTO, E. A.; MElO, A. O.; CAMARGOS, M. A. Análise comparativa entre o CAPM e o C-CAPM na precificação de índices acionários: evidências de mudanças nos coeficientes estimados de 2005 à 2008. Encontro Brasileiro de Finanças, $9,2009$.

COSTA Jr., N.C.A. Será que beta ainda é válido para explicar as variações nas rentabilidades médias das ações? $20^{\circ}$ Encontro Anual da Associação Nacional dos Programas de Pós-graduação em Administração. Finanças, p.335-348, 1996.

DAMODARAN, Aswath. Avaliação de investimentos: ferramentas e técnicas para a determinação do valor de qualquer ativo. / Aswath Damodaran; tradução de Bazán Tecnologia e Linguística (Carlos Henrique Trieschmann e Ronaldo de Almeida rego); supervisão técnica de Eduardo Fortuna. - Rio de Janeiro: Qualitymark Ed., 1997.

DANÍELSSON, J. Financial Risk Forecasting. Wiley Finance, 2011.

DIXIT, A. K; PINDYCK, R. S. Investment under Uncertainty. Princeton University Press, 1994.

ELTON, E. J.; GRUBER, M. J.; BROWN, S. J.; GOETXMANN, W. N. Modern portfolio theory and investment analysis. Ed. 6, p. 705. USA: John Wiley, 2003.

ESTRADA, J. Systematic risk in emerging markets: the D-CAPM. Emerging Markets Quarterly, New York, v. 14, n. 6, p. 365-379, 2002. 
FAMA, Eugene F.; . MACBETH, James D. Risk, return and equilibrium:Empirical tests, Journal of Political Economy, v. 81, p. 607-636. 1973.

FAMA, E.F.; FRENCH, K.R. O modelo de precificação de ativos de capital: teoria e evidencias. ERA - Claássicos, n.103. 2007.

FELLET, Bianca Gabriel. Avaliação de Modelos de Precificação de Ativos no Mercado Acionário Brasileiro. Dissertação de mestrado em Ciências Contábeis do Programa Multiinstitucional e InterRegional de Pós-Graduação em Ciências Contábeis, p.99. Universidade Federal de Brasília, DF, 2016.

GARCIA, P.R.M. Aplicação do CAPM condicional ao mercado acionário brasileiro. Dissertação de mestrado em Administração, p.112. Pontifícia Universidade Católica de São Paulo - PUC/SP, 2015.

GITMAN, L.J. Princípios de administração financeira. / Lawrence J. Gitman; Supervisão de tradução e revisão técnica: Jean Jacques Salim e João Carlos Douat - São Paulo: Editora Harbra, 1997.

GODEIRO, Lucas. CAPM Intertemporal, betas dinâmicos e otimização de portfólios: o país com maior risco é o mais rentável? Disponível em: < https://www.researchgate.net/publication/282785566.> Acesso em 04 de janeiro de 2019.

JAGANNATHAN, R.; WANG, Z. The conditional CAPM and the cross-section of expected returns. Journal of Finance, v.51, p.3-53, 1996.

JENSEN, M. C.; SMITH, C. W. The Theory of Corporate Finance: An Historical Overview. University of Rochester, Managerial Economics Research Center, Graduate School of Management, 1983.Reinprited 1984.

KENDALL, M. G.; HILL, A. B. The analysis of economic time-series-part I. Prices. Journal of the Royal Statistical Society. Series A (General), vol. 116, n. 1, p. 11-34, 1953.

LUCENA, Pierre; MOTTA, L.F.J. Aplicação de um novo modelo de análise de risco na BOVESPA: o D-CAPM. Revista Read, Ed.41, v.10, n.5. 2004.

MACHADO, O.P.; BORTOLUZO, A.B.; SANVICENTE, A.Z.; MARTINS, S.R. Um teste empírico para o CAPM Intertemporal utilizando dados brasileiros. 2011 
MARKOWITZ, H. Portfolio Selection. The Journal of Finance, vol. 7(1), 1952.

MONGRUT, Samuel. Tasas de descuento em Latinoamérica: hechos y

desafios. Centro de Investigación de la Universidad del Pacífico, 2006.

MOTTA, L. F. J.; FORTUNATO, G.; RUSSO, G. Custo de capital próprio em mercados emergentes: resultados de uma investigação empírica no Brasil com o Downside Risk. Encontro da Associação Nacional de Pós-graduação e Pesquisa em Administração, 31., 2007, Rio de Janeiro (RJ). Anais... Rio de Janeiro: ANPAD, 2007.

NIELSEN, L. T.; VASSALOU, M. The Instantaneous capital market line. Economic Theory, volume 28, nº 3, Agosto, 2006.

OLIVEIRA, P.G.S. O custo de capital internacional. Relatório de Projecto de Mestrado em Finanças. ISCTE Business School - Instituto Universitário de Lisboa, 2010.

PAIVA, Felipe Dias. Modelo de precificação de ativos financeiros de fator único: um teste empírico dos modelos CAPM e D-CAPM. Caderno de Pesquisas em Administração, v.12, n.2, p.49-65. 2005.

PEARSON, K. The problem of the random walk. Nature, vol. 72, n. 1865, p. 294, 1905.

REINGANUM, Marc R. Misspecification of capital asset pricing: Empirical Anomalies Based on Earnings' Yields and Market Values. Journal of Financial Economics, n. 9, p. 1946, 1981.

ROCHMAN, R. R.; EID Jr, W. Fundos de investimento ativos e passivos no Brasil: comparando e determinando os seus desempenhos. Encontro da Associação Nacional de Pós-graduação e Pesquisa em Administração, 30., 2006, Salvador (BA). Anais... Rio de Janeiro: ANPAD, 2006.

ROLL, R.A. Critique of the asset pricing theory's tests. Journal of Financial Economics, v.4, p.129-176, 1977.

ROSSI. Estudo de três metodologias para determinação do custo de capital internacional: Análise comparativa e validação dos modelos. São Paulo, 2007.

SANVICEnTE, Antônio Zoratto. Relevância de Prêmio por Risco País no Custo de Capital das Empresas. Rev. adm. contemp., Curitiba, v. 19, n. spe, p. 38-52, 2015. 
SHARPE, W. F. Capital asset prices: A theory of market equilibrium under conditions of risk. Journal of Finance. vol.19, pp.425-442, 1964.

SILVA, C. A. T.; MUNHOZ, D. A. A utilização do lucro contábil como proxy do risco no Brasil. Encontro da Associação Nacional de Pós-graduação e Pesquisa em Administração, 30., 2006, Salvador (BA). Anais... Rio de Janeiro: ANPAD, 2006.

SILVA, Glessia; SILVA, Antonio Vinicius Caldas; ROCHA, Antonio Luiz Dacorso. Custo de capital no setor alimentício brasileiro: um estudo comparativo entre o CAPM tradicional e o CAPM alternativo Revista Alcance, vol. 19, núm. 4, pp. 536-555, 2012.

SOLNIK, B. Why not diversify internationally rather than domestically. Financial Analyst Journal n.30 , p. 48-54, 1977.

STAMBAUGH, R.F. On the exclusion of assets from tests of the two parameter model: A sensitivity analysis. Journal of Financial Economics, v.10, p. 237-268, 1982.

TAMBOSI FILHO, E.; COSTA JÚNIOR, N. C. A.; ROSSETTO, J. R. Testando o CAPM condicional nos mercados brasileiro e norte-americano. Revista de Administração Contemporânea, v. 10, n. 4, p. 143-168, out./dez., 2006.

TSE,Y. K.; TSUI, A. K. C. , A Multivariate Generalized Autoregressive Conditional Heteroscedasticity Model with Time-Varying Correlations. Journal of Business \& Economic Statistics, v. 20, n. 3, pp. 351-36. 2002. 
ANEXO 1 - SÉRIE HISTÓRICA DA COTAÇÃO DAS AÇÕES DO BANCO DO BRASIL - BBAS3

\begin{tabular}{|c|c|c|c|c|c|c|c|c|c|c|c|}
\hline Data & $\begin{array}{c}\text { Preço } \\
\text { fechamento }\end{array}$ & Retorno & Data & $\begin{array}{c}\text { Preço } \\
\text { fechamento }\end{array}$ & Retorno & Data & $\begin{array}{c}\text { Preço } \\
\text { fechamento }\end{array}$ & Retorno & Data & $\begin{array}{c}\text { Preço } \\
\text { fechamento }\end{array}$ & $\begin{array}{c}\text { Retorno } \\
\text { dez/98 }\end{array}$ \\
\hline jan/99 & 1,14 & $-8,80 \%$ & fev/00 & 1,21 & $-5,47 \%$ & abr/01 & 1,40 & $18,64 \%$ & jun/02 & 1,45 & $-31,92 \%$ \\
\hline fev/99 & 1,04 & $-9,65 \%$ & mar/00 & 1,02 & $-15,70 \%$ & mai/01 & 1,27 & $-9,29 \%$ & jul/02 & 1,40 & $-3,45 \%$ \\
\hline mar/99 & 1,10 & $5,77 \%$ & mabr/00 & 0,97 & $-4,90 \%$ & jun/01 & 1,56 & $22,83 \%$ & ago/02 & 1,77 & $26,43 \%$ \\
\hline abr/99 & 1,22 & $10,91 \%$ & jun/00 & 1,05 & $12,90 \%$ & ago/01 & 1,46 & $2,10 \%$ & out/02 & 1,58 & $21,54 \%$ \\
\hline mai/99 & 1,20 & $-1,64 \%$ & jul/00 & 1,02 & $-2,86 \%$ & set/01 & 1,20 & $-17,81 \%$ & nov/02 & 1,64 & $3,80 \%$ \\
\hline jun/99 & 1,14 & $-5,00 \%$ & ago/00 & 1,00 & $-1,96 \%$ & out/01 & 1,25 & $4,17 \%$ & dez/02 & 1,59 & $-3,05 \%$ \\
\hline jul/99 & 0,99 & $-13,16 \%$ & set/00 & 1,02 & $2,00 \%$ & nov/01 & 1,48 & $18,40 \%$ & jan/03 & 1,56 & $-1,89 \%$ \\
\hline ago/99 & 0,93 & $-6,06 \%$ & out/00 & 0,95 & $-6,86 \%$ & dez/01 & 1,72 & $16,22 \%$ & fev/03 & 1,56 & $0,00 \%$ \\
\hline set/99 & 0,98 & $5,38 \%$ & nov/00 & 0,93 & $-2,11 \%$ & jan/02 & 1,46 & $-15,12 \%$ & mar/03 & 1,71 & $9,62 \%$ \\
\hline out/99 & 1,06 & $8,16 \%$ & dez/00 & 0,97 & $4,30 \%$ & fev/02 & 1,69 & $15,75 \%$ & abr/03 & 2,06 & $20,47 \%$ \\
\hline nov/99 & 1,22 & $15,09 \%$ & jan/01 & 1,29 & $32,99 \%$ & mar/02 & 1,88 & $11,24 \%$ & mai/03 & 2,48 & $20,39 \%$ \\
\hline dez/99 & 1,36 & $11,48 \%$ & fev/01 & 1,17 & $-9,30 \%$ & abr/02 & 2,19 & $16,49 \%$ & jun/03 & 2,13 & $-14,11 \%$ \\
\hline jan/00 & 1,28 & $-5,88 \%$ & mar/01 & 1,18 & $0,85 \%$ & mai/02 & 2,13 & $-2,74 \%$ & jul/03 & 2,31 & $8,45 \%$ \\
\hline
\end{tabular}




\begin{tabular}{|c|c|r|c|c|r|r|r|r|r|r|r|}
\hline Data & $\begin{array}{c}\text { Preço } \\
\text { fechamento }\end{array}$ & Retorno & Data & $\begin{array}{c}\text { Preço } \\
\text { fechamento }\end{array}$ & Retorno & Data & $\begin{array}{c}\text { Preço } \\
\text { fechamento }\end{array}$ & Retorno & $\begin{array}{c}\text { Preço } \\
\text { Data }\end{array}$ & $\begin{array}{c}\text { fechamento } \\
\text { Retorno }\end{array}$ \\
\hline ago/03 & 2,50 & $8,23 \%$ & out/04 & 4,60 & $12,47 \%$ & dez/05 & 6,85 & $7,54 \%$ & fev/07 & 11,14 & $-1,33 \%$ \\
\hline set/03 & 2,60 & $4,00 \%$ & nov/04 & 5,17 & $12,39 \%$ & jan/06 & 8,70 & $27,01 \%$ & mar/07 & 10,83 & $-2,78 \%$ \\
\hline out/03 & 3,05 & $17,31 \%$ & dez/04 & 5,28 & $2,13 \%$ & fev/06 & 8,93 & $2,64 \%$ & abr/07 & 11,30 & $4,34 \%$ \\
\hline nov/03 & 3,98 & $30,49 \%$ & jan/05 & 5,02 & $-4,92 \%$ & mar/06 & 9,01 & $0,90 \%$ & mai/07 & 12,86 & $13,81 \%$ \\
\hline dez/03 & 3,90 & $-2,01 \%$ & fev/05 & 5,03 & $0,20 \%$ & abr/06 & 9,85 & $9,32 \%$ & jun/07 & 13,59 & $5,68 \%$ \\
\hline jan/04 & 3,31 & $-15,13 \%$ & mar/05 & 4,81 & $-4,37 \%$ & mai/06 & 9,13 & $-7,31 \%$ & jul/07 & 14,42 & $6,11 \%$ \\
\hline fev/04 & 3,52 & $6,34 \%$ & abr/05 & 4,75 & $-1,25 \%$ & jun/06 & 8,12 & $-11,06 \%$ & ago/07 & 13,74 & $-4,72 \%$ \\
\hline mar/04 & 3,78 & $7,39 \%$ & mai/05 & 4,99 & $5,05 \%$ & jul/06 & 8,10 & $-0,25 \%$ & set/07 & 15,12 & $10,04 \%$ \\
\hline abr/04 & 3,10 & $-17,99 \%$ & jun/05 & 5,14 & $3,01 \%$ & ago/06 & 7,80 & $-3,70 \%$ & out/07 & 15,32 & $1,32 \%$ \\
\hline mai/04 & 3,38 & $9,03 \%$ & jul/05 & 5,08 & $-1,17 \%$ & set/06 & 7,71 & $-1,15 \%$ & nov/07 & 15,61 & $1,89 \%$ \\
\hline jun/04 & 3,65 & $7,99 \%$ & ago/05 & 5,67 & $11,61 \%$ & out/06 & 8,44 & $9,47 \%$ & dez/07 & 15,00 & $-3,91 \%$ \\
\hline jul/04 & 3,74 & $2,47 \%$ & set/05 & 7,05 & $24,34 \%$ & nov/06 & 9,61 & $13,86 \%$ & jan/08 & 14,43 & $-3,80 \%$ \\
\hline ago/04 & 3,94 & $5,35 \%$ & out/05 & 6,72 & $-4,68 \%$ & dez/06 & 10,39 & $8,12 \%$ & fev/08 & 13,97 & $-3,19 \%$ \\
\hline set/04 & 4,09 & $3,81 \%$ & nov/05 & 6,37 & $-5,21 \%$ & jan/07 & 11,29 & $8,66 \%$ & mar/08 & 11,49 & $-17,75 \%$ \\
\hline
\end{tabular}




\begin{tabular}{|l|c|r|l|l|r|r|r|r|r|r|r|}
\hline Data & $\begin{array}{c}\text { Preço } \\
\text { fechamento }\end{array}$ & Retorno & Data & $\begin{array}{c}\text { Preço } \\
\text { fechamento }\end{array}$ & Retorno & Data & $\begin{array}{c}\text { Preço } \\
\text { fechamento }\end{array}$ & Retorno & Data & $\begin{array}{c}\text { Preço } \\
\text { fechamento }\end{array}$ & \begin{tabular}{c} 
Retorno \\
\hline abr/08
\end{tabular} \\
14,37 & $25,07 \%$ & jun/09 & 11,55 & $0,96 \%$ & ago/10 & 16,61 & $-6,16 \%$ & out/11 & 16,26 & $4,30 \%$ \\
\hline mai/08 & 16,30 & $13,43 \%$ & jul/09 & 12,89 & $11,60 \%$ & set/10 & 18,88 & $13,67 \%$ & nov/11 & 15,27 & $-6,09 \%$ \\
\hline jun/08 & 13,17 & $-19,20 \%$ & ago/09 & 14,37 & $11,48 \%$ & out/10 & 19,46 & $3,07 \%$ & dez/11 & 15,14 & $-0,85 \%$ \\
\hline jul/08 & 12,64 & $-4,02 \%$ & set/09 & 17,26 & $20,11 \%$ & nov/10 & 19,41 & $-0,26 \%$ & jan/12 & 17,37 & $14,73 \%$ \\
\hline ago/08 & 12,05 & $-4,67 \%$ & out/09 & 15,59 & $-9,68 \%$ & dez/10 & 18,68 & $-3,76 \%$ & fev/12 & 17,76 & $2,25 \%$ \\
\hline set/08 & 11,60 & $-3,73 \%$ & nov/09 & 17,15 & $10,01 \%$ & jan/11 & 17,70 & $-5,25 \%$ & mar/12 & 16,84 & $-5,18 \%$ \\
\hline out/08 & 7,53 & $-35,09 \%$ & dez/09 & 16,59 & $-3,27 \%$ & fev/11 & 17,88 & $1,02 \%$ & abr/12 & 15,30 & $-9,14 \%$ \\
\hline nov/08 & 7,36 & $-2,26 \%$ & jan/10 & 15,69 & $-5,42 \%$ & mar/11 & 17,92 & $0,22 \%$ & mai/12 & 13,01 & $-14,97 \%$ \\
\hline dez/08 & 7,64 & $3,80 \%$ & fev/10 & 16,88 & $7,58 \%$ & abr/11 & 17,58 & $-1,90 \%$ & jun/12 & 12,89 & $-0,92 \%$ \\
\hline jan/09 & 7,39 & $-3,27 \%$ & mar/10 & 17,04 & $0,95 \%$ & mai/11 & 17,11 & $-2,67 \%$ & jul/12 & 14,39 & $11,64 \%$ \\
\hline fev/09 & 7,38 & $-0,14 \%$ & abr/10 & 17,12 & $0,47 \%$ & jun/11 & 17,24 & $0,76 \%$ & ago/12 & 15,39 & $6,95 \%$ \\
\hline mar/09 & 9,08 & $23,04 \%$ & mai/10 & 15,05 & $-12,09 \%$ & jul/11 & 16,19 & $-6,09 \%$ & set/12 & 16,65 & $8,19 \%$ \\
\hline abr/09 & 9,94 & $9,47 \%$ & jun/10 & 14,28 & $-5,12 \%$ & ago/11 & 16,59 & $2,47 \%$ & out/12 & 14,55 & $-12,61 \%$ \\
\hline mai/09 & 11,44 & $15,09 \%$ & jul/10 & 17,70 & $23,95 \%$ & set/11 & 15,59 & $-6,03 \%$ & nov/12 & 14,78 & $1,58 \%$ \\
\hline
\end{tabular}




\begin{tabular}{|c|c|c|c|c|c|c|c|c|c|c|c|}
\hline Data & \begin{tabular}{|c|}
$\begin{array}{c}\text { Preço } \\
\text { fechamento }\end{array}$ \\
\end{tabular} & Retorno & Data & $\begin{array}{c}\text { Preço } \\
\text { fechamento }\end{array}$ & Retorno & Data & $\begin{array}{c}\text { Preço } \\
\text { fechamento }\end{array}$ & Retorno & Data & $\begin{array}{c}\begin{array}{c}\text { Preço } \\
\text { fechamento }\end{array} \\
\end{array}$ & Retorno \\
\hline $\operatorname{dez} / 12$ & 17,50 & $18,40 \%$ & $\mathrm{fev} / 14$ & 15,67 & $-0,25 \%$ & $\mathrm{abr} / 15$ & 21,84 & $16,17 \%$ & jun/16 & 15,68 & $5,16 \%$ \\
\hline $\mathrm{jan} / 13$ & 16,68 & $-4,69 \%$ & $\operatorname{mar} / 14$ & 17,54 & $11,93 \%$ & mai/15 & 19,01 & $-12,96 \%$ & jul/16 & 19,21 & $22,51 \%$ \\
\hline $\mathrm{fev} / 13$ & 18,00 & $7,91 \%$ & $\mathrm{abr} / 14$ & 18,01 & $2,68 \%$ & jun/15 & 20,55 & $8,10 \%$ & ago/16 & 21,31 & $10,93 \%$ \\
\hline $\mathrm{mar} / 13$ & 19,13 & $6,28 \%$ & mai/14 & 17,58 & $-2,39 \%$ & $\mathrm{jul} / 15$ & 18,66 & $-9,20 \%$ & set/16 & 21,05 & $-1,22 \%$ \\
\hline $\mathrm{abr} / 13$ & 17,51 & $-8,47 \%$ & jun/14 & 19,42 & $10,47 \%$ & ago/15 & 15,20 & $-18,54 \%$ & out/16 & 27,04 & $28,46 \%$ \\
\hline mai/13 & 17,77 & $1,48 \%$ & $\mathrm{jul} / 14$ & 21,66 & $11,53 \%$ & set/15 & 13,18 & $-13,29 \%$ & nov/16 & 26,42 & $-2,29 \%$ \\
\hline jun/13 & 15,67 & $-11,82 \%$ & ago/14 & 27,41 & $26,55 \%$ & out $/ 15$ & 13,84 & $5,01 \%$ & $\operatorname{dez} / 16$ & 26,11 & $-1,17 \%$ \\
\hline $\mathrm{jul} / 13$ & 16,05 & $2,43 \%$ & set/14 & 20,03 & $-26,92 \%$ & nov/15 & 14,25 & $2,96 \%$ & $\mathrm{jan} / 17$ & 28,92 & $10,76 \%$ \\
\hline ago/13 & 16,89 & $5,23 \%$ & out/14 & 21,96 & $9,64 \%$ & $\mathrm{dez} / 15$ & 13,10 & $-8,07 \%$ & fev/17 & 30,77 & $6,40 \%$ \\
\hline set/13 & 19,19 & $13,62 \%$ & nov/14 & 23,53 & $7,15 \%$ & $\mathrm{jan} / 16$ & 12,31 & $-6,03 \%$ & $\operatorname{mar} / 17$ & 31,48 & $2,31 \%$ \\
\hline out/13 & 22,09 & $15,11 \%$ & $\mathrm{dez} / 14$ & 19,12 & $-18,74 \%$ & $\mathrm{fev} / 16$ & 12,03 & $-2,27 \%$ & $\mathrm{abr} / 17$ & 30,63 & $-2,70 \%$ \\
\hline nov/13 & 19,14 & $-13,35 \%$ & $\mathrm{jan} / 15$ & 16,62 & $-13,08 \%$ & $\mathrm{mar} / 16$ & 17,75 & $47,55 \%$ & mai/17 & 26,60 & $-13,16 \%$ \\
\hline $\operatorname{dez} / 13$ & 18,35 & $-4,13 \%$ & $\mathrm{fev} / 15$ & 19,15 & $15,22 \%$ & $a b r / 16$ & 19,85 & $11,83 \%$ & jun/17 & 25,23 & $-5,15 \%$ \\
\hline jan/14 & 15,71 & $-14,39 \%$ & $\operatorname{mar} / 15$ & 18,80 & $-1,83 \%$ & mai/16 & 14,91 & $-24,89 \%$ & $\mathrm{jul} / 17$ & 27,02 & $7,09 \%$ \\
\hline
\end{tabular}




\begin{tabular}{|c|c|r|c|c|r|}
\hline Data & $\begin{array}{c}\text { Preço } \\
\text { fechamento }\end{array}$ & Retorno & Data & $\begin{array}{c}\text { Preço } \\
\text { fechamento }\end{array}$ & Retorno \\
\hline ago/17 & 29,09 & $7,66 \%$ & out/18 & 42,22 & $45,14 \%$ \\
\hline set/17 & 33,15 & $13,96 \%$ & nov/18 & 44,50 & $5,40 \%$ \\
\hline out/17 & 32,71 & $-1,33 \%$ & dez/18 & 46,49 & $4,47 \%$ \\
\hline nov/17 & 28,62 & $-12,50 \%$ & & & \\
\hline dez/17 & 30,51 & $6,60 \%$ & & & \\
\hline jan/18 & 38,05 & $24,71 \%$ & & & \\
\hline fev/18 & 40,08 & $5,34 \%$ & & & \\
\hline mar/18 & 39,64 & $-1,10 \%$ & & & \\
\hline abr/18 & 35,46 & $-10,54 \%$ & & & \\
\hline mai/18 & 29,54 & $-16,69 \%$ & & & \\
\hline jun/18 & 27,95 & $-5,38 \%$ & & & \\
\hline jul/18 & 31,71 & $13,45 \%$ & & & \\
\hline ago/18 & 29,64 & $-6,53 \%$ & & & \\
\hline set/18 & 29,09 & $-1,86 \%$ & & & \\
\hline
\end{tabular}




\section{ANEXO 2 - ESTIMATIVAS E RESÍDUO DO MODELO ESTRUTURAL UTILIZADO PARA A ESTIMAÇÃO DO BETA DINÂMICO ESTRUTURAL}

Tabela 15: Estimativa da variância Modelo Estrutural

\begin{tabular}{cccc}
\hline Ativo & Nível & Irregular & Beta \\
\hline BBAS3 & 0,00 & 0,00 & 0,0027 \\
\hline \multicolumn{4}{c}{ Fonte: Elaboração própria. }
\end{tabular}

Tabela 16: Diagnóstico dos resíduos do modelo estrutural.

\begin{tabular}{ccccc}
\hline Ativo & $\mathbf{Q 1}_{1}(\mathbf{5})$ & $\mathbf{Q}_{\mathbf{1}}(\mathbf{1 0})$ & $\mathbf{Q}_{\mathbf{1}}(\mathbf{1 5})$ & $\mathbf{Q}_{\mathbf{1}}(\mathbf{2 0})$ \\
\hline BBAS3 & 7,54 & 40,41 & 57,63 & 62,86 \\
\hline \multicolumn{7}{l}{ Fonte: } \\
\hline
\end{tabular}

